\title{
Fascin limits Myosin activity within Drosophila border cells to control substrate stiffness and promote migration
}

\author{
Maureen C Lamb ${ }^{1}$, Chathuri P Kaluarachchi ${ }^{2}$, Thiranjeewa I Lansakara ${ }^{2}$, \\ Samuel $\mathbf{Q}$ Mellentine ${ }^{1}$, Yiling Lan ${ }^{2}$, Alexei V Tivanski ${ }^{2}$, Tina L Tootle ${ }^{1 *}$
}

${ }^{1}$ Anatomy and Cell Biology, University of lowa Carver College of Medicine, lowa City, United States; ${ }^{2}$ Department of Chemistry, University of lowa, lowa City, United States
*For correspondence: tina-tootle@uiowa.edu

Competing interest: The authors declare that no competing interests exist.

Funding: See page 25

Received: 27 April 2021 Preprinted: 28 April 2021 Accepted: 11 October 2021 Published: 26 October 2021

Reviewing Editor: Derek Applewhite, Reed College, United States

(c) Copyright Lamb et al. This article is distributed under the terms of the Creative Commons Attribution License, which permits unrestricted use and redistribution provided that the original author and source are credited.

\begin{abstract}
A key regulator of collective cell migrations, which drive development and cancer metastasis, is substrate stiffness. Increased substrate stiffness promotes migration and is controlled by Myosin. Using Drosophila border cell migration as a model of collective cell migration, we identify, for the first time, that the actin bundling protein Fascin limits Myosin activity in vivo. Loss of Fascin results in: increased activated Myosin on the border cells and their substrate, the nurse cells; decreased border cell Myosin dynamics; and increased nurse cell stiffness as measured by atomic force microscopy. Reducing Myosin restores on-time border cell migration in fascin mutant follicles. Further, Fascin's actin bundling activity is required to limit Myosin activation. Surprisingly, we find that Fascin regulates Myosin activity in the border cells to control nurse cell stiffness to promote migration. Thus, these data shift the paradigm from a substrate stiffness-centric model of regulating migration, to uncover that collectively migrating cells play a critical role in controlling the mechanical properties of their substrate in order to promote their own migration. This understudied means of mechanical regulation of migration is likely conserved across contexts and organisms, as Fascin and Myosin are common regulators of cell migration.
\end{abstract}

\section{Introduction}

Cell migration is an essential process driving both development and cancer metastasis. During these processes, cells often migrate as groups or collectives, rather than single cells (Friedl and Gilmour, 2009). Collective cell migration requires that cell-cell adhesions be maintained amongst the cells to support cluster cohesion (De Pascalis and Etienne-Manneville, 2017). Additionally, many collective cell migrations occur in an invasive manner with the group of cells migrating between other cells or through basement membranes (Chang et al., 2019). During invasive migration, the environment puts mechanical forces on the migrating cells, causing them to respond by changing their shape and stiffness, and by modifying properties of their environment, such as extracellular matrix (ECM) composition (Aguilar-Cuenca et al., 2014; Gasparski et al., 2017; Eble and Niland, 2019). Therefore, stiffness has emerged as a critical regulator of collective cell migration.

During invasive, collective cell migration the group or cluster of cells must generate force necessary to invade through the ECM or other cells. Stiffness of the substrate is considered the primary regulator of the migrating cell's stiffness and ability to migrate (Aguilar-Cuenca et al., 2014). For example, increased substrate stiffness contributes to cancer cell migration and metastasis (Gasparski et al., 2017; Oakes, 2018; Eble and Niland, 2019). Indeed, hard matrices induce migration in breast cancer cells (Ren et al., 2021), and increased substrate stiffness promotes epithelial to mesenchymal 
transitions (Nieto and Cano, 2012). While the role of substrate stiffness in promoting cell migration is well-established, most of these studies utilized in vitro culture systems. Therefore, it remains poorly understood how migrating cells are regulated in their native environments by the stiffness of their endogenous substrates.

A master regulator of cellular stiffness is Non-Muscle Myosin II (subsequently referred to as Myosin). Myosin is a force generating actin motor (Vicente-Manzanares et al., 2009; Aguilar-Cuenca et al., 2014). It is composed of two copies of three subunits: two heavy chains, two essential light chains, and two regulatory light chains (MRLC; Vicente-Manzanares et al., 2009; Aguilar-Cuenca et al., 2014). Myosin activation is regulated through phosphorylation of its regulatory light chains. This phosphorylation occurs through a number of kinases, including Myosin light chain kinase (MLCK) and Rho-associated kinase (Rok), and dephosphorylation occurs through phosphatases, such as protein phosphatase $1 \mathrm{c}$ (PP1c) and its catalytic subunit, Myosin binding subunit (Mbs Vicente-Manzanares et al., 2009; Aguilar-Cuenca et al., 2014). Myosin generates cortical tension by associating with and acting upon cortical F-actin; this regulates cell stiffness which can influence cell migration (Butcher et al., 2009; Aguilar-Cuenca et al., 2014). Importantly, Myosin regulates stiffness in both cellular substrates and migrating cells during many different cell migrations (Lo et al., 2000; VicenteManzanares et al., 2009; Mohan et al., 2015). Additionally, Myosin not only generates mechanical force within a cell but aids in sensing and responding to external forces applied to the cell (Butcher et al., 2009; Vicente-Manzanares et al., 2009; Aguilar-Cuenca et al., 2014).

A recently discovered regulator of Myosin is Fascin. Fascin is an F-actin binding protein that bundles or cross-links actin filaments into fibers (Jayo and Parsons, 2010; Hashimoto et al., 2011). However, recent studies demonstrate that there are many non-canonical roles for Fascin (Lamb and Tootle, 2020). One of these non-canonical functions of Fascin is the regulation of Myosin (Elkhatib et al., 2014). Increasing concentrations of Fascin in an in vitro system decreased Myosin ATP consumption and motor speed along actin filaments (Elkhatib et al., 2014). These data suggest that Fascin limits Myosin activity (Elkhatib et al., 2014). Whether Fascin limits Myosin activity to control substrate stiffness and thereby cell migration remains unknown. Notably, Fascin has well-established roles in promoting cell migration (Lamb and Tootle, 2020). Fascin aids in the formation of cell migratory structures like filopodia (Hashimoto et al., 2011) and invadopodia (Li et al., 2010). Fascin promotes many types of cell migrations in development and disease, including cancer metastasis (Ma and Machesky, 2015). Investigation of Fascin's role in promoting cell migration has primarily focused on Fascin as an F-actin bundler and it is unknown if Fascin limits Myosin activity to regulate collective cell migration.

An ideal model to uncover the role of Fascin in regulating Myosin during collective cell migration in a native context is Drosophila border cell migration. Border cell migration occurs during Stage 9 (S9) of oogenesis. During S9, the follicle is composed of an oocyte and 15 germline-derived nurse cells that are surrounded by a layer of somatic epithelial cells called follicle cells (Spradling, 1993). Surrounding the follicle cells is a layer of ECM that envelopes the follicle (Spradling, 1993). Inside the follicle, however, there is limited evidence of any ECM (Medioni and Noselli, 2005). At the beginning of S9, a group of 8-10 follicle cells are specified as border cells and delaminate from the epithelium to start their migration (Montell, 2003). The border cells migrate invasively and collectively between the nurse cells until they reach the nurse cell-oocyte boundary (Figure 1A and B; Montell, 2003). Border cell migration is a cell-on-cell migration in which the nurse cells are the substrate for the migration, there is only a small puncta of ECM on the border cell cluster as it migrates (Medioni and Noselli, 2005) and border cell migration is largely independent of Integrin-based adhesions (Dinkins et al., 2008; Llense and Martín-Blanco, 2008). Importantly, similar to other types of migration, the stiffness of the nurse cell substrate regulates both the stiffness of the border cells and their migration (Aranjuez et al., 2016). Therefore, border cell migration is a powerful model for studying invasive, collective cell migration as the cluster of migrating cells can be visualized in its native context using both fixed and live imaging. Additionally, the factors that regulate border cell migration play conserved roles in other invasive, collective cell migrations, including cancer metastasis (Montell et al., 2012; Stuelten et al., 2018). Indeed, both Fascin and Myosin play roles in promoting cancer metastasis (Hashimoto et al., 2011; Aguilar-Cuenca et al., 2014) and on-time border cell migration (Figure 1C, Edwards and Kiehart, 1996; Lamb et al., 2020). We previously found that Fascin (Drosophila Singed, Sn) is required for both border cell delamination and proper protrusion localization (Lamb et al., 2020). Both loss and activation of Myosin result in similar phenotypes of delayed delamination and mislocalized 


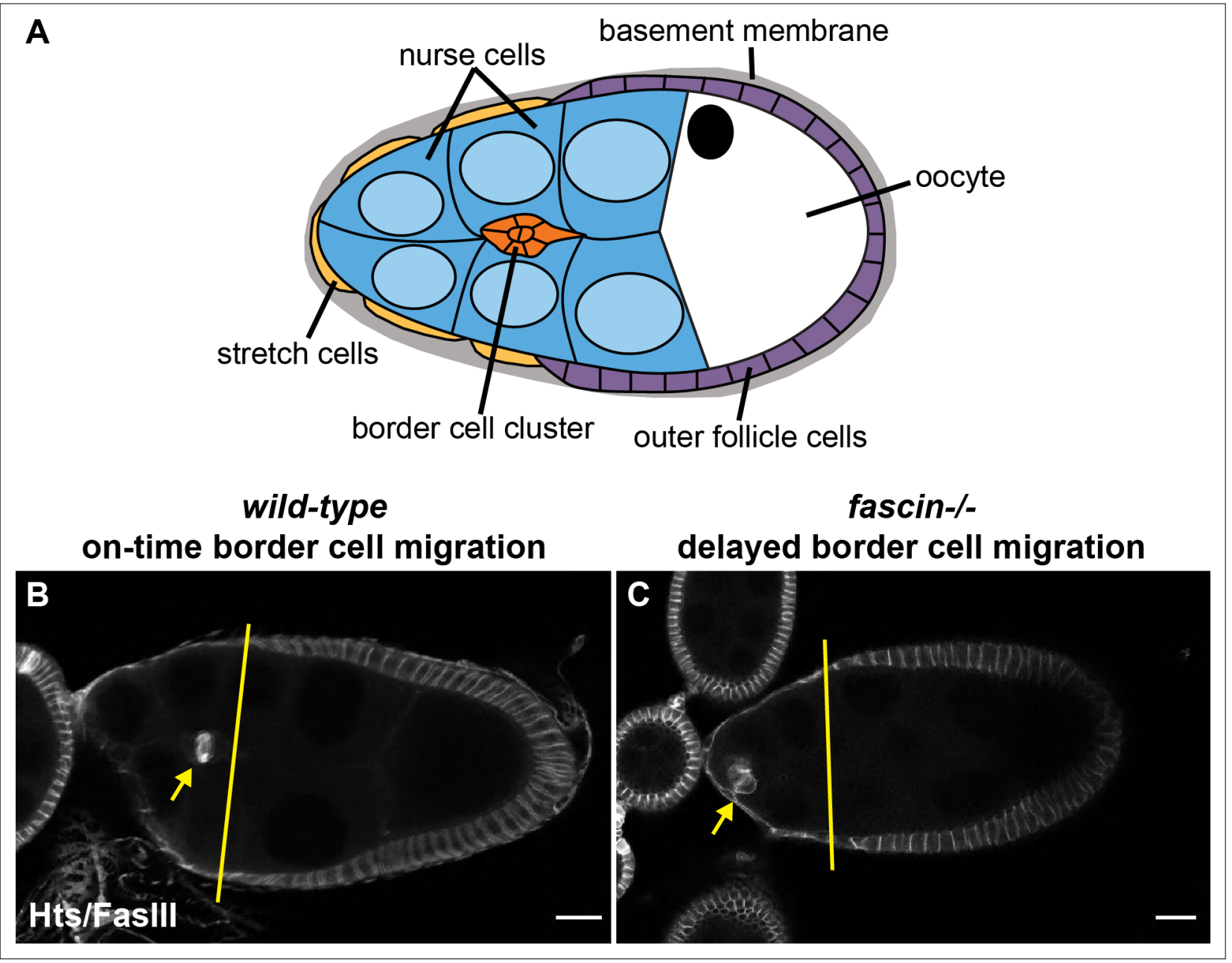

Figure 1. Fascin is required for on-time border cell migration during Stage 9. (A) Schematic of a Stage 9 Drosophila follicle. The nurse cells (blue) are the substrate for the migrating border cell cluster (orange); the direction of border cell migration is to the right. The follicle is surrounded by a layer of somatic epithelial cells which include the outer follicle cells (purple) and the stretch cells (gold). These cells are surrounded by a layer of basement membrane (grey). (B-C). Maximum projections of 2-4 confocal slices of Stage 9 follicles of the indicated genotypes. Border cell stain (Hts/Faslll, white).

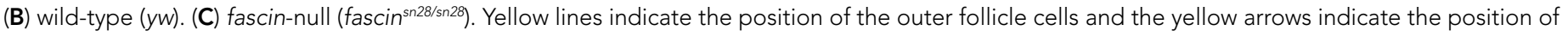
the border cell cluster. In wild-type follicles, the border cells are in line with the position of the outer follicle cells (B), whereas in fascin mutant follicles the border cells are significantly behind the outer follicle cells, indicating that loss of Fascin results in delayed border cell migration during Stage 9 of oogenesis (C). All genotypes are listed in Table 1.

border cell cluster protrusions (Majumder et al., 2012; Aranjuez et al., 2016; Mishra et al., 2019). These data suggest that the cycling of Myosin between active and inactive forms controls border cell migration. Thus, border cell migration is an ideal system to uncover the relationship of Fascin and Myosin during collective cell migration.

Here, we demonstrate for the first time that Fascin inhibits Myosin activity in vivo. Loss of Fascin significantly increases the level of active Myosin, reduces Myosin dynamics, and increases nurse cell (aka substrate) stiffness as quantified by atomic force microscopy (AFM) nanoindentation technique. Reducing Myosin in fascin mutant follicles rescues border cell migration delays, indicating that Fascin's tight regulation of Myosin activity is critical for on-time migration. Further, a phosphomimetic form of Fascin that precludes F-actin bundling is unable to limit Myosin activation, supporting the prior model that Fascin limits Myosin activity by tightly bundling F-actin and preventing Myosin binding to actin filaments (Elkhatib et al., 2014). We used RNAi knockdown and rescue experiments to assess the cell-specific roles of Fascin in regulating Myosin activity and nurse cell stiffness. Based on the literature, we expected that Fascin would primarily function within the nurse cells to control both substrate stiffness and Myosin activity within both the nurse cells and border cells. Surprisingly, we find that 
knocking down Fascin in the border cells increases the level of active Myosin on both the border cells and the nurse cells, and increases the stiffness of the nurse cells. Similarly, re-expressing Fascin in only the border cells of fascin mutants restores normal Myosin activity levels and stiffness of the nurse cells. These unexpected findings suggest that migrating cells influence the mechanobiology of their substrate to promote their migration. Supporting this, increasing Rok activity in the border cells also results in increased nurse cell stiffness, indicating this migratory cell regulation of substrate stiffness is not a Fascin-specific phenomenom. Together these findings lead to the following model: Fascin acts primarily within the migrating border cells to limit Myosin activation which controls the stiffness of the both the border cells and their substrate, the nurse cells, to promote on-time migration. It is likely that this regulation of Myosin by Fascin and thereby, migrating cells controlling substrate stiffness, is a conserved means of promoting collective cell migration.

\section{Results}

\section{Fascin inhibits Myosin activation in the Drosophila follicle}

Previous data demonstrates that Fascin can inhibit the activity of Myosin in vitro (Elkhatib et al., 2014). Fascin functions in both the nurse cells and the border cells to promote on-time border cell migration (Lamb et al., 2020). Additionally, during border cell migration Myosin generates forces in the nurse cells that push upon the border cells, causing the border cells to activate Myosin and stiffen (Aranjuez et al., 2016), suggesting that the nurse cells control the stiffness of the border cell cluster. Based on these observations, we hypothesized that Fascin may regulate Myosin activity in the Drosophila follicle, specifically the nurse cells, to promote border cell migration.

To test this hypothesis, we assessed if Fascin limits Myosin activity in the Drosophila follicle. Myosin is activated via phosphorylation on its regulatory light chain subunit (MRLC). To assess changes in Myosin activation in the follicle, we stained follicles using an antibody against phosphorylated MRLC (pMRLC); wild-type and fascin-null follicles were stained in the same tube to account for staining variability. We observe a striking increase in active MRLC along both the nurse cell and border cell membranes of fascin-null follicles (Figure 2B compared to A, blue arrows and $B^{\prime}$ compared to $A^{\prime}$, orange arrows). We quantified levels of active MRLC by measuring the relative fluorescence intensity of pMRLC on the nurse cell and border cell membranes (Figure 2C-D; for example quantifications see Figure 2-figure supplement 1A,B). Briefly, for the nurse cell quantifications, 3 line segments per follicle were drawn across nurse cell-nurse cell membranes and the fluorescence intensity peak for pMRLC was normalized to phalloidin intensity at the same point; phalloidin intensity is not affected by loss of Fascin (Figure 2-figure supplement 1C). Concurrent border cell staining ensured we did not measure across a border cell cluster protrusion. The three values were then averaged for a single image (for example quantifications see Figure 2-figure supplement 1A,B). For border cell intensity, the border cell cluster was traced using the phalloidin or border cell stain and the mean fluorescence intensity for PMRLC was measured and normalized to the mean fluorescence intensity of pMRLC of the same shape in the nurse cell cytoplasm (for example quantifications see Figure 2-figure supplement 1A). We used the nurse cell cytoplasm pMRLC stain as the background for the border cell measurement because there is no available antibody that works against MRLC. Importantly, nurse cell cytoplasmic PMRLC intensity (Figure 2-figure supplement 1D) and Myosin heavy chain (Drosophila Zipper) protein levels are not significantly different between wild-type and fascin-null follicles (Figure 2-figure supplement 1E,F). For increased clarity, throughout the entire manuscript, all graphs quantifying MRLC activity on the nurse cell membranes are shown using blue circles and MRLC activity on the border cell cluster are shown using orange circles. We find that there is a significant increase in active MRLC intensity on the fascin-null nurse cell membranes compared to wild-type follicles (Figure 2C, p < 0.0001). Additionally, active MRLC is also significantly increased on the border cell cluster when Fascin is lost (Figure 2D, $\mathrm{p}<0.0001$ ). Further, we assessed the spatial distribution of active MRLC on the nurse cell membranes surrounding the border cell cluster. In both wild-type and fascin mutant follicles, we observe active Myosin enriched on nurse cell membranes in front, behind, and on the sides of the migrating cluster (Figure 2A and B). While the intensity of pMRLC staining is higher in the fascin mutants indicating higher Myosin activation, there does not seem to be a change in the spatial distribution of active Myosin on the border cell cluster. 

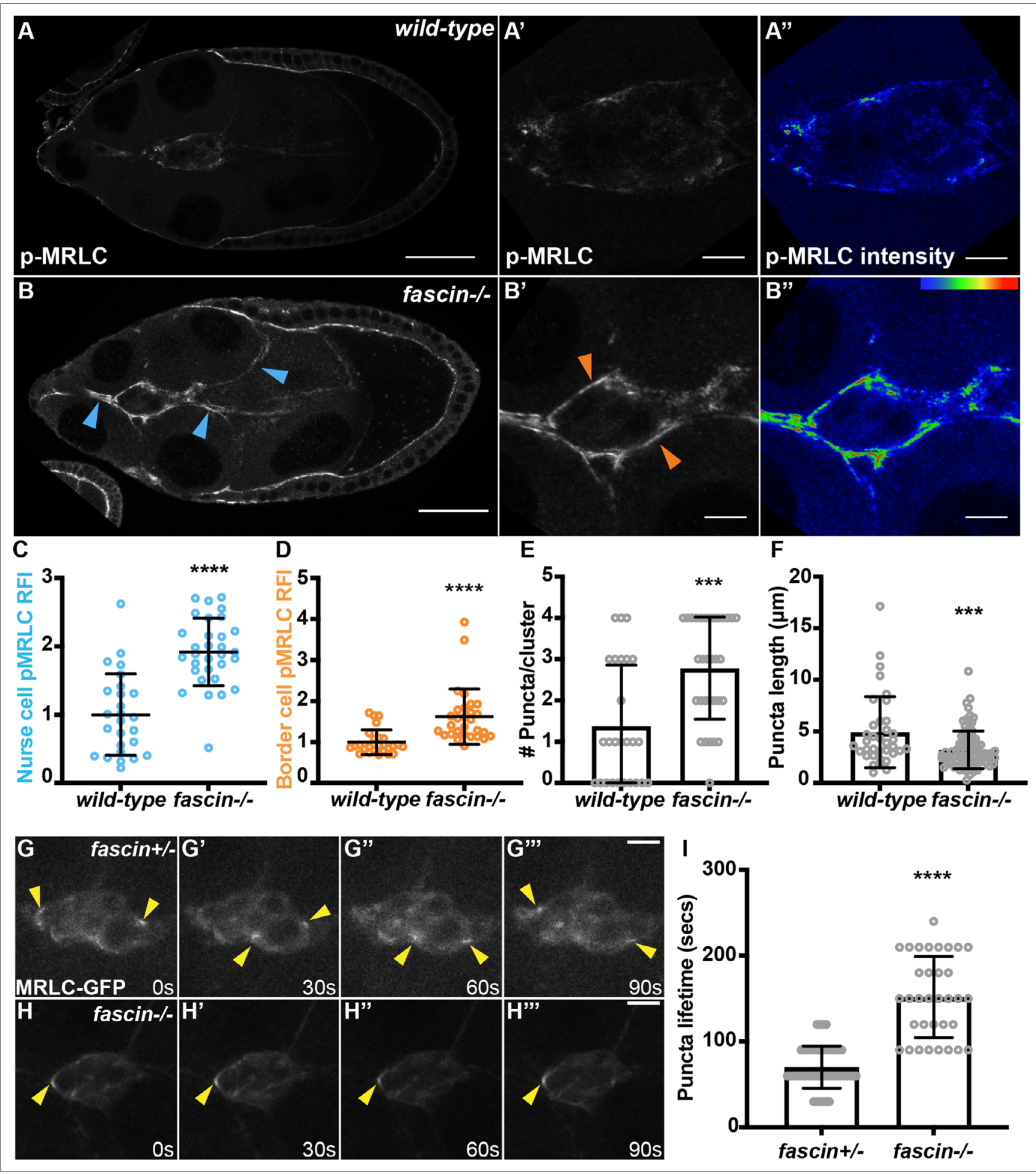

Figure 2. Fascin limits Myosin activity in the Stage 9 Drosophila follicle. (A-B") Maximum projections of $2-4$ confocal slices of Stage 9 follicles of the indicated genotypes. (A-A', B-B') phospho-MRLC (pMRLC, white). (A", $\mathbf{B}^{\prime \prime}$ ) pMRLC pseudocolored with Rainbow RGB, red = highest intensity pixels.

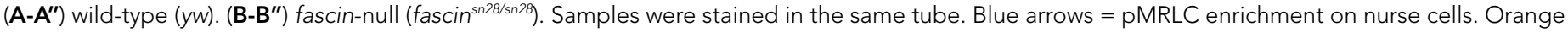
arrows $=$ pMRLC enrichment on border cell cluster. Scale bars $=50 \mu \mathrm{m}$ in A, B and $10 \mu \mathrm{m}$ in $\mathbf{A}^{\prime}-\mathbf{A}^{\prime \prime}, \mathbf{B}^{\prime}-\mathbf{B}^{\prime \prime}$. (C-F) Graphs of quantification of pMRLC intensity and localization at the nurse cell membranes $(\mathbf{C})$ and border cell cluster $(\mathbf{D}, \mathbf{E}, \mathbf{F})$ in wild-type and fascin-null follicles. Each circle represents a follicle. Error bars $=\mathrm{SD}$. ${ }^{\star \star \star} \mathrm{p}<0.001,{ }^{\star \star \star \star} \mathrm{p}<0.0001$ (unpaired t-test). In $\mathbf{C}$, peak pMRLC intensity was quantified at the nurse cell membranes and normalized to phalloidin staining in the same follicle, three measurements were taken per follicle and averaged. In D, pMRLC intensity on the border cell cluster was quantified and normalized to background pMRLC staining in the same follicle. For examples of the quantifications in $\mathbf{C}$ and $\mathbf{D}$ see

Figure 2 continued on next page 
Figure 2 continued

Figure 2-figure supplement 1. In $\mathbf{E}$, the number of Myosin puncta per cluster was manually counted. In $\mathbf{F}$, the maximum length of each Myosin puncta was measured. (G-H'"') Maximum projection of three confocal slices from time-lapse imaging of MRLC-GFP in the indicated genotypes. Direction of migration is to the right. Scale bars $=10 \mu \mathrm{m}$. (G-G'"') Control follicle (fascin ${ }^{\text {sn28/t; }}$ MRLC-GFP/+; Video 1). (H-H'"') fascin-null follicle (fascin ${ }^{\text {sn28/sn28; }}$ MRLC-GFP/+; Video 2). (I) Quantification of puncta lifetime from time-lapse imaging for control $(n=4)$ and fascin-null $(n=4)$ MRLC-GFP expressing follicles. Puncta lifetime was defined as the amount of time elapsed from when a punctum first appeared to when it completely disappeared. ${ }^{* \star \star} \mathrm{p}<$ 0.0001 (unpaired t-test). Error bars = SD. fascin-null follicles have increased pMRLC on the the nurse cell membranes $(\mathbf{B}, \mathbf{C})$ and border cell cluster $\left(\mathbf{B}^{\prime}\right.$, D) compared to wild-type follicles (A, A', C, D). The border cell clusters in fascin-null mutants also have increased Myosin puncta number but decreased length (E, F). fascin mutants have significantly slowed Myosin dynamics $\left(\mathbf{H}-\mathbf{H}^{\prime \prime \prime}, \mathbf{l}\right)$ compared to the control clusters $\left(\mathbf{G}-\mathbf{G} \mathbf{I}^{\prime \prime}, \mathbf{I}\right)$. All genotypes are listed in Table 1.

The online version of this article includes the following source data and figure supplement(s) for figure 2:

Source data 1. Source data for Figure $2 C-F$ and $I$.

Figure supplement 1. Myosin activity assessments.

Figure supplement 1-source data 1. Source data for Figure 2-figure supplement 1C, D and F.

Figure supplement 1-source data 2. Source data for Figure 2-figure supplement 1E.

We also quantified changes in active MRLC puncta number and length on the border cell cluster (Figure 2E and F; see Methods for quantification details). Briefly, the puncta on each border cell cluster were manually counted and the maximum length of each punctum was measured from maximum projections of 2-4 confocal slices using ImageJ software. Loss of Fascin increases puncta number but decreases puncta length (Figure $2 E$ and F, p < 0.001). Together these results demonstrate that Fascin limits Myosin activation in the Drosophila S9 follicle on both the nurse cell membranes and the border cell cluster, providing the first evidence that Fascin regulates Myosin activity in vivo.

\section{Fascin limits Myosin dynamics on the migrating border cell cluster}

We next wanted to determine how Fascin influences Myosin dynamics during border cell migration. In addition to the level of activation, the localization and dynamics of Myosin influence invasive migration (Vicente-Manzanares et al., 2009; Majumder et al., 2012; Aguilar-Cuenca et al., 2014; Aranjuez et al., 2016). Indeed, during border cell migration, dynamic cycles of Myosin activation and inactivation at the cluster membrane are essential for proper migration (Aranjuez et al., 2016). We visualized Myosin dynamics on the border cell cluster using a C-terminally GFP-tagged MRLC (MRLC-GFP; Drosophila Spaghetti Squash, Sqh), under the control of its endogenous promoter. Previous data demonstrates that MRLC-GFP is highly expressed on the border cell cluster during migration and accumulates in transient puncta on the cluster; these puncta depend on Myosin activation, suggesting they are sites of active Myosin (Majumder et al., 2012). Using live imaging, we find in control follicles, MRLC-GFP puncta appear and disappear rapidly on the border cell cluster (Figure 2G-G'"',

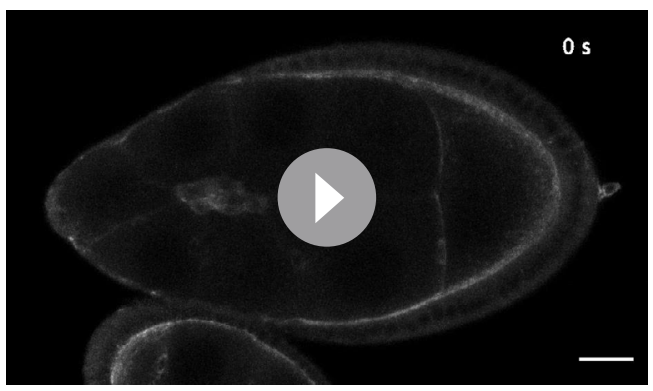

Video 1. Myosin dynamics in control follicle. Video of Stage 9 control MRLC-GFP expressing follicle

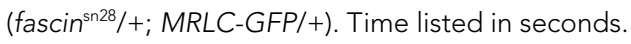
Images were acquired every $30 \mathrm{~s}$. Anterior is to the right. Scale bar $=20 \mu \mathrm{m}$. The control cluster displays Myosin dynamics in which Myosin puncta appear and disappear rapidly on the border cell cluster. All genotypes are listed in Table 1.

https://elifesciences.org/articles/69836/figures\#video1 Video 1). However, in the fascin-null follicles, the MRLC-GFP puncta dynamics are much slower (Figure 2H-H"', Video 2). We quantified this change in MRLC-GFP dynamics by measuring puncta lifetime on the cluster (Figure 2I). The control follicles display an average puncta lifetime of $70.2 \mathrm{~s}$, while in fascin-null follicles the average puncta lifetime is $151.8 \mathrm{~s}$ (Figure 2l, p < 0.0001). These results suggest that Fascin limits Myosin dynamics on the migrating border cell cluster.

\section{Fascin regulates nurse cell stiffness}

As increased Myosin activity increases actomyosin contractility and cell stiffness, we next wanted to directly measure the stiffness of fascin-null follicles. Substrate stiffness is thought to be a driving regulator of cell migration and migrating cell stiffness 


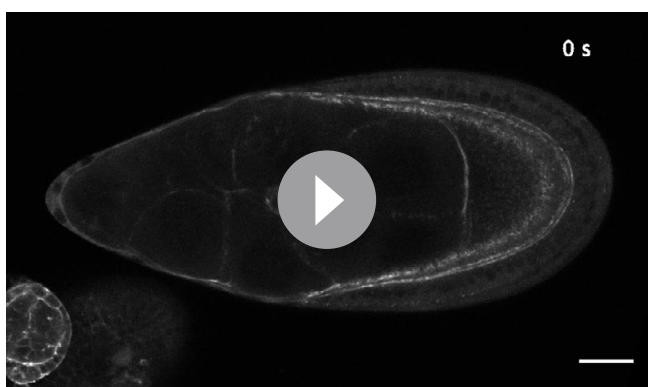

Video 2. Myosin dynamics in fascin-null follicle. Video of Stage 9 fascin-null MRLC-GFP expressing follicle (fascin ${ }^{\text {sn28/sn28; }}$ MRLC-GFP/+). Time listed in seconds. Images were acquired every $30 \mathrm{~s}$. Anterior is to the right. Scale bar $=20 \mu \mathrm{m}$. Loss of Fascin results in slower Myosin dynamics, with Myosin puncta appearing and remaining longer than in controls (see Video 1). All genotypes are listed in Table 1.

https://elifesciences.org/articles/69836/figures\#video2
(Di Martino et al., 2016; Gasparski et al., 2017; Oakes, 2018; Ren et al., 2021), therefore we aimed to directly quantify nurse cell stiffness. AFM is a standard method to directly measure mechanical properties of biological tissues (Kreplak, 2016). AFM can be used to quantify the elastic modulus, which is a measurement of how easily an elastic material is deformed when a known amount of force is applied (Kreplak, 2016). A high elastic modulus value corresponds to a stiff tissue. We used AFM nanoindentation technique to quantify the stiffness of fascin-null and wildtype nurse cells (Crest et al., 2017; Chen et al., 2019). The nurse cells are the substrate for the border cells and their stiffness regulates border cell migration and cluster stiffness (Aranjuez et al., 2016). Notably, during S9, the nurse cells are surrounded by a layer of stretch follicle cells and a basement membrane that envelopes the entire follicle (Figure 3A). Previous measurements on Drosophila follicles using AFM established that there is significant difference in stiffness between the basement membrane and the underlying nurse cells (Crest et al., 2017; Chen et al., 2019). These different tissues stiffnesses can be separated by using different indentation ranges to indent the AFM probe into just the basement membrane or to indent deeper into the nurse cells (Figure 3B; Chlasta et alo, 2017). Thus, by using two indentation ranges to fit the mechanical response, we can quantify the distinct stiffness of the basement membrane versus that of the underlying nurse cells (Chlasta et al., 2017).

We used AFM and the Hertzian elastic contact model to calculate the stiffness of wild-type and fascin-null S9 follicles (Figure 3C). For increased clarity, throughout the entire manuscript all graphs quantifying stiffness by AFM are represented using green circles. For an indentation range of 0-100 nm, which probes the basement membrane, wild-type follicles have an average stiffness of $24.2 \mathrm{kPa}$ and fascin-null follicles have a similar average stiffness of $26.5 \mathrm{kPa}$ (Figure 3D, p > 0.05). However, for an indentation range of 310-550 nm, which probes the nurse cell stiffness, wild-type follicles have an average stiffness of $10.1 \mathrm{kPa}$ while fascin-null follicles have a significantly increased average stiffness of $25.9 \mathrm{kPa}$ (Figure 3D, $\mathrm{p}<0.0001$ ). Thus, the stiffness of the fascin-null nurse cells is $>2 \times$ higher than wild-type nurse cells. Together these results demonstrate that loss of Fascin increases the stiffness of the nurse cells in S9 Drosophila follicles.

\section{Fascin limits Myosin activity to promote border cell migration}

As increased stiffness of the nurse cells or border cells inhibits border cell migration (Aranjuez et al., 2016), we hypothesized that the increased Myosin activity in fascin-null follicles contributes to the previously characterized border cell migration delays (Lamb et al., 2020). To address this hypothesis, we first used a pharmacological inhibitor of Myosin and assessed the effect on border cell migration. Follicles were incubated for $2 \mathrm{hr}$ in either control media or $200 \mu \mathrm{M}$ of Y-27632, a Rho inhibitor previously used to reduce Myosin activity in Drosophila follicles (He et al., 2010). This inhibitor reduces activated Myosin levels on both the nurse cells and border cells (Figure 4-figure supplement 1A,B). We then employed our previously developed method to quantify delays in border cell migration during S9, which takes the ratio of the distance the border cells have migrated from the anterior end of the follicle to the distance of the outer follicle cells from the anterior end of the follicle (see schematic Figure 4A; Lamb et al., 2020). We call this value the migration index; for increase clarity, throughout the entire manuscript all migration indexes data are shown in magenta. A migration index of approximately one indicates on-time migration during S9, while a value less that one indicates delayed migration and a value greater than one indicates an accelerated migration. As we previously established, loss of Fascin significant delays migration (Figure 1C, Lamb et al., 2020). Here, we find that inhibiting Myosin activity with Y-27632 in fascin-null follicles restores on-time border cell 


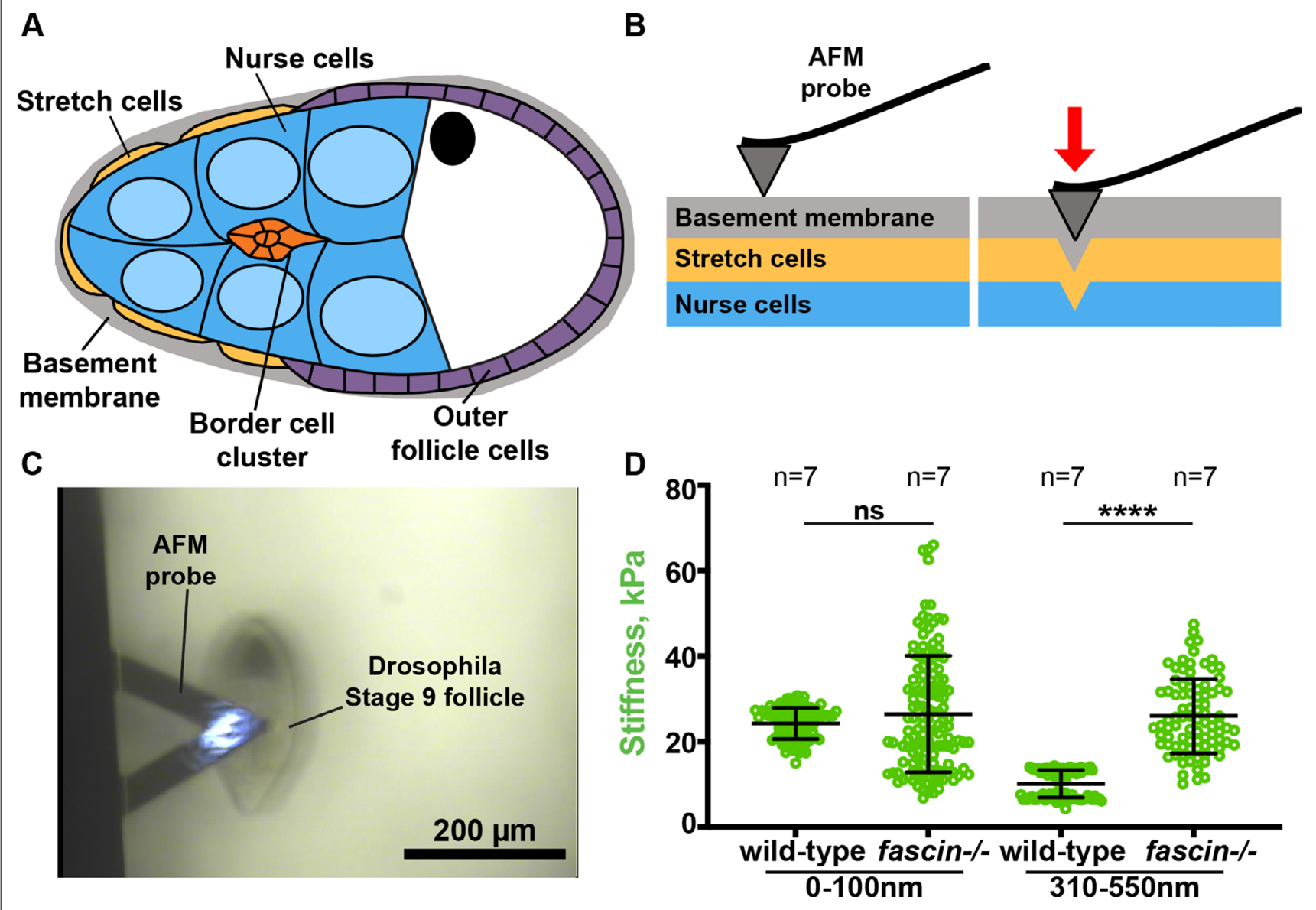

Figure 3. Fascin regulates nurse cell stiffness in the Drosophila follicle. (A) Schematic of Stage 9 Drosophila follicle. The nurse cells (blue) are surrounded by a layer of stretch cells (gold) and basement membrane (gray). (B) Schematic of AFM probe indentation through the basement membrane (gray) and stretch cells (gold) into the underlying nurse cells (blue). (C) Bright-field image of AFM probe over a Stage 9 follicle. (D) Graph of nurse cell stiffness $(\mathrm{kPa})$ in wild-type or fascin-null follicles as measured by AFM. Each circle represents a single indentation. Error bars $=\mathrm{SD}$. ns indicates $\mathrm{p}>0.05$, ${ }^{* \star *} \mathrm{p}<0.0001$ (unpaired t-test). Loss of Fascin significantly increases the stiffness of the nurse cells (D). All genotypes are listed in Table 1.

The online version of this article includes the following source data for figure 3 :

Source data 1. Source data Figure 3F.

migration compared to the fascin-null control (Figure 4C-D and G, migration index 1.1 compared to 0.78 ) and is not significantly different from the wild-type control (Figure $4 B$ and $G$, migration index 1.1 compared to 0.95 ).

As loss of Fascin increases Myosin activity on both the nurse cells and the border cells, we next sought to determine whether increased Myosin activity on the nurse cells and/or border cells is responsible for delays in border cell migration. We used the UAS/GAL4 system to express an RNAi against MRLC (Drosophila Sqh) to knockdown Myosin in fascin-null mutants in different cell types (see schematic of cell specific knockdown in Figure 6A) - the germline (mata GAL4), somatic (c355 GAL4), or border cells (c306 GAL4). Unfortunately, knockdown of Myosin in the somatic (c355 GAL4) or border cells (c306 GAL4) was lethal, however knockdown of Myosin in the germline (mat $\alpha$ GAL4) was viable. Germline knockdown of MRLC in fascin mutants significantly decreased active Myosin levels on the nurse cells compared to fascin-null controls (Figure 4-figure supplement 1C). However, it fails to restore normal levels of active Myosin on the border cell cluster, as Myosin activation remains significantly increased compared to the wild-type control and is not signficantly different than the fascin-null control (Figure 4-figure supplement 1D). We next assessed whether altering Myosin activity within the nurse cells can restore on-time border cell migration in fascin-null mutants using the migration index quantification (see schematic, Figure 4A). Germline knockdown of MRLC in fascin mutant follicles rescues border cell migration (Figure 4E, $F$ and $H$, migration index 0.91 compared to 

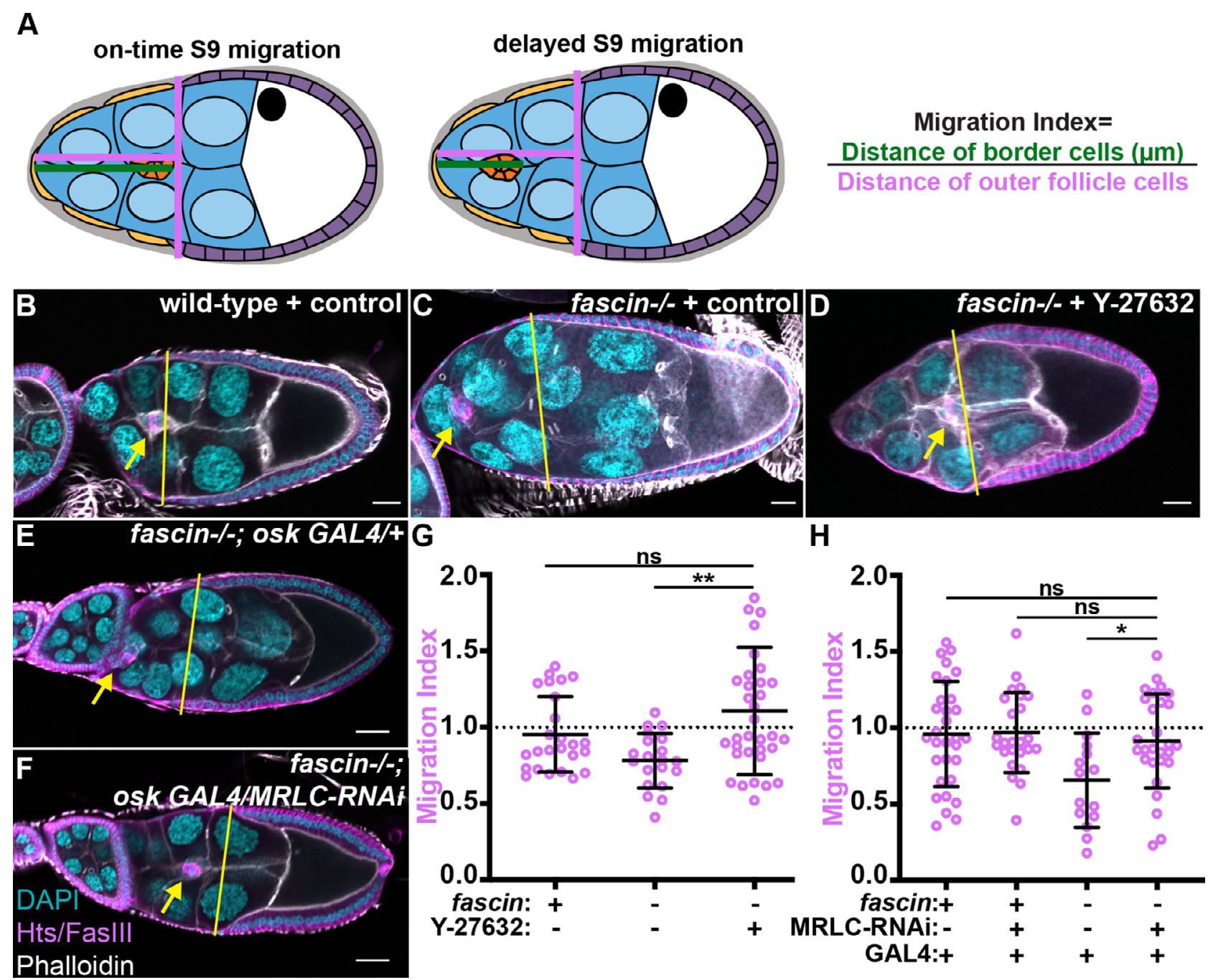

H

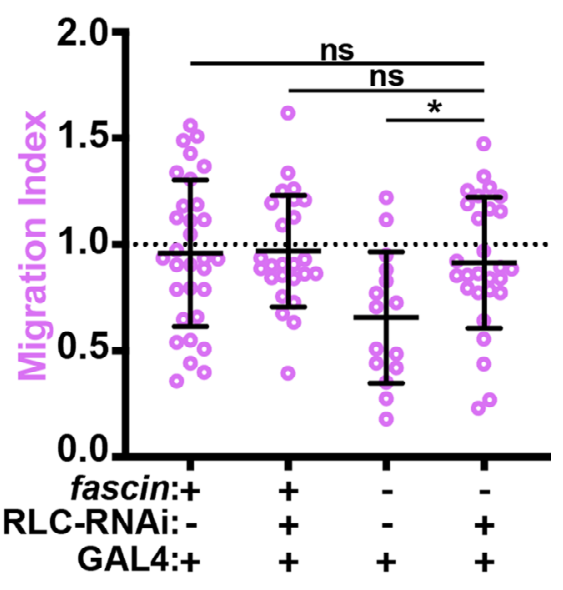

Figure 4. Reducing Myosin activity rescues border cell migration in fascin mutant follicles. (A) Schematics of the migration index quantification for on-time and delayed border cell migration during Stage 9. The migration index is the distance the border cell cluster has migrated (green line) divided by the distance of the outer follicle cells from the anterior end of the follicle (magenta line). A value of $\sim 1$ indicates on-time migration, a value $<1$ indicates delayed migration and a value $>1$ indicates accelerated migration. (B-F) Maximum projections of 2-4 confocal slices of Stage 9 follicles of the indicated genotypes. Merged images: Hts/FasIll (magenta, border cell migration stain), phalloidin (white), and DAPI (cyan). Yellow lines = outer follicle cell distance. Yellow arrows = border cell cluster. Black boxes have been added behind text. Scale bars $=20 \mu \mathrm{m}$. (B) wild-type (yw) treated with control

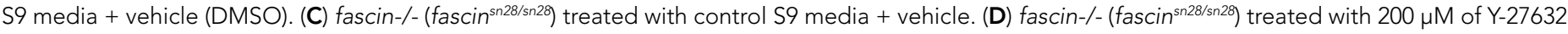
(E) fascin sn28/sn28; oskar GAL4 (2)/+ (F) fascin sn28/sn28; oskar GAL4 (2)/MRLC-RNAi. (G, H) Migration index quantification of the indicated genotypes. Dotted line at $1=$ on time migration. Circle $=$ Stage 9 follicle. Lines = averages and error bars $=$ SD. ns indicates $p>0.05,{ }^{\star} p<0.05,{ }^{\star \star} p<0.01$ (one-way ANOVA with Tukey's multiple comparison test). Pharmacological inhibition of Myosin activity rescues border cell migration delays in fascin mutant follicles (B-D, G). Similarly, germline knockdown of MRLC restores on-time border cell migration in fascin mutants, suggesting that increased active Myosin in the nurse cells of fascin mutants leads to the border cell migration delays $(\mathbf{E}, \mathbf{F}, \mathbf{H})$. All genotypes are listed in Table 1.

The online version of this article includes the following source data and figure supplement(s) for figure 4:

Source data 1. Source data for Figure 4G, H.

Figure supplement 1. Pharmacological inhibition of Myosin and germline MRLC knockdown reduce active Myosin in the follicle.

Figure supplement 1-source data 1. Source data for Figure 4-figure supplement 1A-D. 
0.65). Together these results suggest that Fascin is required to limit Myosin activity within the nurse cells to promote on-time border cell migration.

\section{Phosphorylation of Fascin controls its ability to limit Myosin activity}

Previous data demonstrated that in vitro Fascin can limit Myosin activation; however, the mechanism of how Fascin regulates Myosin activity is unknown (Elkhatib et al., 2014). It was hypothesized that Fascin's ability to tightly bundle F-actin precludes Myosin from being able to bind to actin filaments and generate force (Elkhatib et al., 2014). Phosphorylation of Fascin at serine 52 (S52, mammalian S39) inhibits its F-actin bundling function (Yamakita et al., 1996; Ono et al., 1997). If Fascin's bundling activity is required to limit Myosin activation, we would predict that global expression (actin 5 c GAL4) of phosphomimetic Fascin (S52E) in fascin-null mutants would fail to suppress the increased active

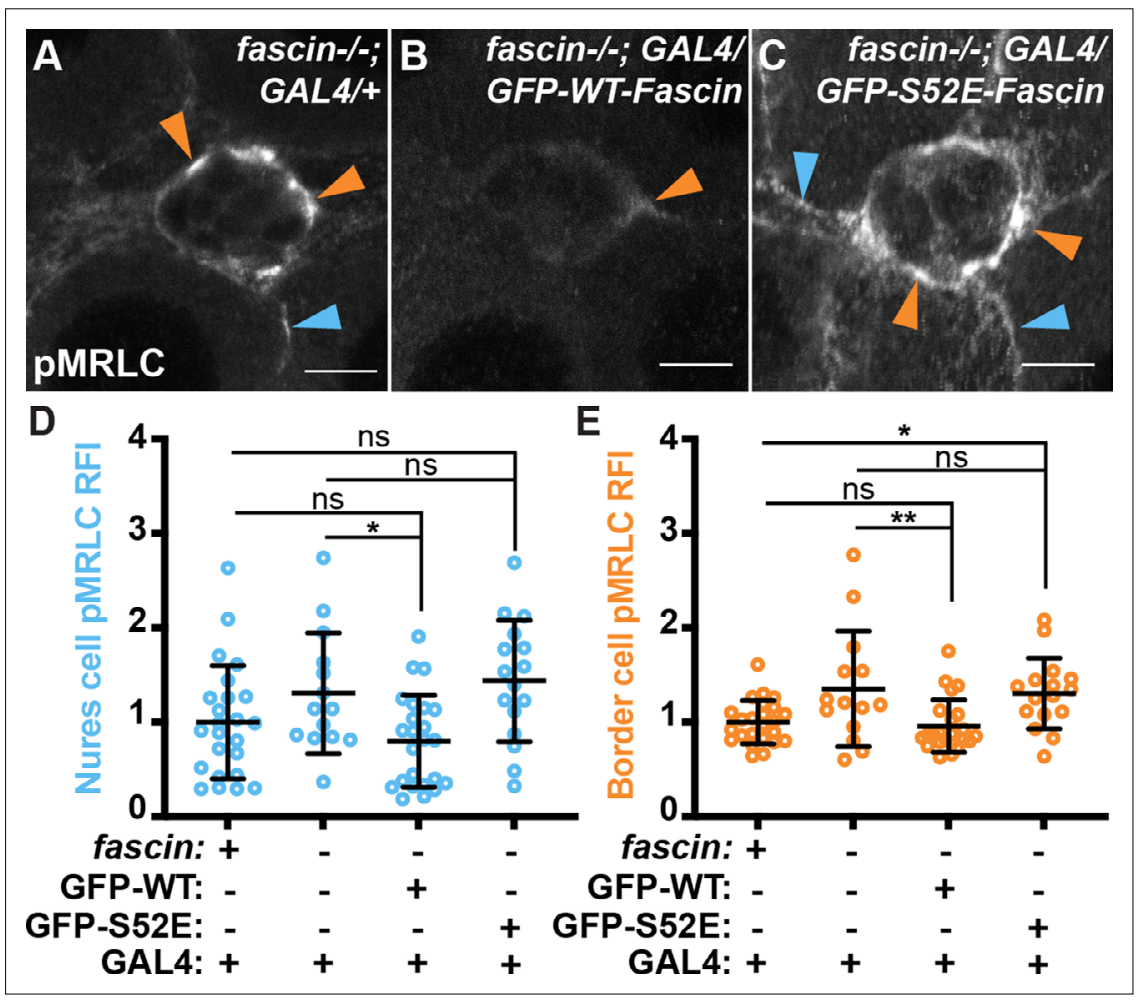

Figure 5. Phosphorylated Fascin fails to limit Myosin activation. (A-C) Maximum projections of 2-4 confocal slices of Stage 9 follicles of the indicated genotypes stained for phospho-MRLC (pMRLC, white). Blue arrows = pMRLC enrichment on surrounding nurse cells. Orange arrows = pMRLC enrichment on border cell cluster. Scale bars $=10 \mu \mathrm{m}$. (A) fascin mutant with global GAL4 (fascin ${ }^{\text {sn28/sn28; }}$ actin5c GAL4/+). (B) Global GFP-Fascin expression in fascin mutant (fascin ${ }^{\text {sn28/sn28; }}$ actin5c GAL4/UAS-GFP-Fascin). (C) Global GFP-Fascin-S52E expression in fascin mutant (fascin ${ }^{\text {sn28/sn28; }}$ actin5c GAL4/UAS-GFP-Fascin-S52E). (D, E) Graphs of quantification of pMRLC intensity at the nurse cell membranes (D) and border cell cluster (E) in the indicated genotypes. Each circle represents a follicle. Error bars $=$ SD. ns indicates $p>0.05,{ }^{*} p<0.05,{ }^{\star \star} p<0.01$ (One-way ANOVA with Tukey's multiple comparison test). In $\mathbf{D}$, peak PMRLC intensity was quantified at the nurse cell membranes and normalized to phalloidin staining in the same follicle, three measurements were taken per follicle and averaged. In E, pMRLC intensity on the border cell cluster was quantified and normalized to background staining in the same follicle. Restoring wild-type Fascin expression in both the somatic and germline cells of fascin mutant follicles (B) significantly reduces activated Myosin enrichment on the nurse cell membranes (D) and border cell cluster $(\mathbf{E})$ compared to the fascin-null control $(\mathbf{B}, \mathbf{D}, \mathbf{E})$. Whereas expressing a phosphomimetic form of Fascin in a fascin mutant (C) does not alter activated Myosin on the nurse cell membranes (D) or border cell cluster (E). All genotypes are listed in Table 1.

The online version of this article includes the following source data and figure supplement(s) for figure 5 :

Source data 1. Source data for Figure 5D, E.

Figure supplement 1. Phosphorylation of Fascin regulates border cell migration.

Figure supplement 1-source data 1. Source data Figure 5-figure supplement 1C. 
Myosin. As a control, we find that global expression of wild-type Fascin (GFP-Fascin) in fascin mutant follicles significantly reduces active MRLC enrichment on both the nurse cell membranes (Figure 5) and border cell cluster (Figure 5B, orange arrow and E). Conversely, when the phosphomimetic form of Fascin (GFP-Fascin S52E) is expressed in fascin-null mutants, we observe high levels of active Myosin on both the nurse cell membranes (Figure 5C, blue arrows and D) and border cell cluster (Figure 5C, orange arrows and E) that are not significantly different than the fascin mutant control (Figure 5A, D and E). These data support the model that Fascin limits Myosin activity by bundling $\mathrm{F}$-actin and precluding Myosin's ability to bind to actin filaments.

As we found that tight regulation of Myosin activity by Fascin is critical for on-time border cell migration (Figure 4), and expression of phosphomimetic Fascin (S52E) in fascin mutant follicles fails to restore normal levels of Myosin activity (Figure 5B-E), we expected it would also fail to fully rescue the delays in border cell migration. We previously found global expression (actin $5 \mathrm{c}$ GAL4) of wild-type Fascin in fascin mutant follicles restores on-time border cell migration (Lamb et alo, 2020). As expected, when we quantify the migration index (described in Figure 4A) for fascin mutant follicles with global expression of phosphomimetic Fascin (S52E), we find it only partially rescues delays in border cell migration (Figure 5-figure supplement 1C, migration index 0.90 compared to 0.80 ). Together these data indicate Fascin functions in other ways besides bundling F-actin and limiting Myosin activity to promote on-time border cell migration.

\section{Fascin acts in the border cells to control substrate stiffness}

Previous evidence demonstrated that the stiffness of the nurse cells regulates border cell cluster stiffness as indicated by active Myosin levels and on-time border cell migration (Aranjuez et al., 2016). Since Fascin is required in both the nurse cells and the border cells to promote on-time border cell migration (Lamb et alo, 2020), we wanted to determine which cells Fascin acts in to regulate Myosin activation. To test this, we used the UAS/GAL4 system to express a Fascin RNAi construct to knockdown Fascin in specific cell types (Figure 6A) - the germline (mat $\alpha$ GAL4), somatic (c355 GAL4), or border cells (c306 GAL4) - and analyzed how loss of Fascin in these different cells affects Myosin activation throughout the follicle. We have previously validated the use of

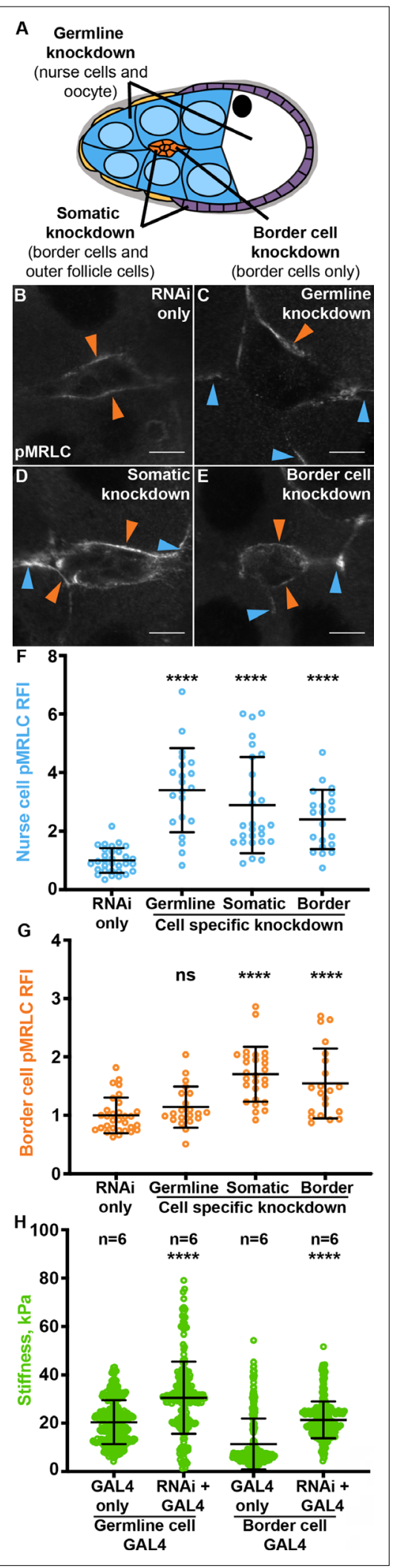

Figure 6. Germline Fascin knockdown increases Myosin activation on the nurse cells while somatic Fascin knockdown increases Myosin activation on both the border and nurse cells. (A) Schematic of Figure 6 continued on next page 
Figure 6 continued

cell-specific Fascin knockdown for each GAL4 driver: germline knockdown will knockdown Fascin in the nurse cells (blue) and oocyte (white), somatic cell knockdown will knockdown Fascin in the border cells (orange) and follicle cells (purple and gold), and the border cell knockdown will knockdown Fascin in only the border cells (orange). (B-E) Maximum projections of 2-4 confocal slices of Stage 9 follicles of the indicated genotypes stained for phospho-MRLC (pMRLC, white). Orange arrows $=$ pMRLC enrichment on border cell cluster. Blue arrows $=$ pMRLC enrichment on surrounding nurse cells. Scale bars $=10 \mu \mathrm{m}$. (B) RNAi only (fascin RNAi/+). (C) Germline knockdown of Fascin (mat $\alpha$ GAL4(3)/fascin RNAi). (D) Somatic cell knockdown of Fascin (c355 GAL4/+; fascin RNAi/+). (E) Border cell knockdown of Fascin (c306 GAL4/+; fascin RNAi/+). (F, G) Graphs of quantification of pMRLC intensity at the nurse cell membranes $(\mathbf{F})$ and border cell cluster (G) in the indicated genotypes. Each circle represents a follicle. Error bars $=$ SD. ns indicates $p>$ $0.05,{ }^{* \star * *} p<0.0001$ (One-way ANOVA with Tukey's multiple comparison test). In F, peak pMRLC intensity was quantified at the nurse cell membranes and normalized to phalloidin staining in the same follicle, three measurements were taken per follicle and averaged. In G, pMRLC intensity on the border cell cluster was quantified and normalized to background staining in the same follicle. (H) Graph of nurse cell stiffness $(\mathrm{kPa})$ of the indicated genotypes as measured by AFM. Each circle represents a single indentation. $\star \star \star * p<0.0001$ (unpaired t-test). Error bars $=S D$. Fascin regulates Myosin activation in the germline $(\mathbf{C}, \mathbf{F}, \mathbf{G})$ and somatic cells (D, E, F, G). Knockdown of Fascin in the germline cells increases Myosin activity and stiffness of the nurse cells $(\mathbf{C}, \mathbf{F}, \mathbf{H})$. Knockdown of Fascin in either all somatic cells or only the border cells increases Myosin activity and stiffness of the nurse cells $(\mathbf{D}, \mathbf{E}, \mathbf{F}$, H), and Myosin activity in the border cell cluster (D, E, G). All genotypes are listed in Table 1.

The online version of this article includes the following source data for figure 6 :

Source data 1. Source data for Figure 6F-H.
UAS/GAL4 system to knockdown Fascin in these cell types (Lamb et al., 2020).

Based on the literature, we hypothesized knockdown of Fascin in the germline would increase Myosin activation in both the nurse cells and border cells, while knockdown of Fascin in the border cells would only increase Myosin activation in the border cells. We observe, as expected, knockdown of Fascin in the germline results in a significant increase in pMRLC (active MRLC) enrichment on the nurse cell membranes (Figure 6C, blue arrows and $F, p<0.0001$ ). However, knockdown down of Fascin in the germline unexpectedly fails to alter active MRLC enrichment on the border cell cluster (Figure 6C, orange arrow and $\mathrm{G}, \mathrm{p}>0.05$ ). We next knocked down Fascin in all the somatic cells or just the border cells and anticipated that this would lead to a significant increase in active MRLC on the border cell cluster but not the nurse cells. As expected, we observe a significant increase of active MRLC on the border cell cluster when Fascin is knocked down in the border cells (Figure 6D, E and G, orange arrows, $p<0.0001$ ). Surprisingly, knockdown of Fascin in the somatic or just the border cells also significantly increased active MRLC enrichment on the nurse cells (Figure 6D, E and F, blue arrows, $p$ $<0.0001$ ). These data surprisingly suggest that knockdown of Fascin in the border cells increases border cell stiffness and this, in turn, induces the stiffening of their substrate, the nurse cells.

Further, we used AFM to directly assess the changes in nurse cell stiffness of our cell specific Fascin knockdowns. Germline knockdown of Fascin results in nurse cells that are $1.5 \mathrm{X}$ stiffer than their GAL4 control (Figure $6 H, p<0.0001$ ), while border cell knockdown results in nurse cells that are $1.8 \mathrm{X}$ stiffer than their GAL4 control (Figure $6 \mathrm{H}, \mathrm{p}<0.0001$ ). Together these data demonstrate the unexpected finding that Fascin acts the border cell cluster to regulate the stiffness of the surrounding nurse cell substrate (Figure 8).

\section{Border cell stiffness controls Myosin activity in its substrate}

Our RNAi experiments indicate that Fascin acts primarily in the border cells to control Myosin activation and nurse cell stiffness. If this is true, then restoring Fascin expression in only the somatic cells of a fascin mutant follicle, including the border cells, should restore normal Myosin activation in both the border cells and the nurse cells, and normal nurse cell stiffness. Indeed, we find that expressing GFP-Fascin in the somatic cells of fascin-null follicles significantly reduces active MRLC enrichment on both the nurse cell and border cell membranes compared to the fascin-null control (Figure 7A-E, $p<0.0001)$. Further, restoring Fascin expression in the somatic cells of fascin-null follicles significantly reduced the stiffness of the nurse cells compared to the fascin-null control (Figure 7, $19.4 \mathrm{kPa}$ compared to $38.9 \mathrm{kPa}, \mathrm{p}<0.0001)$. Together our data indicate that Fascin acts in the border cells to regulate the stiffness of both the border cell cluster and its substrate, the nurse cells. 


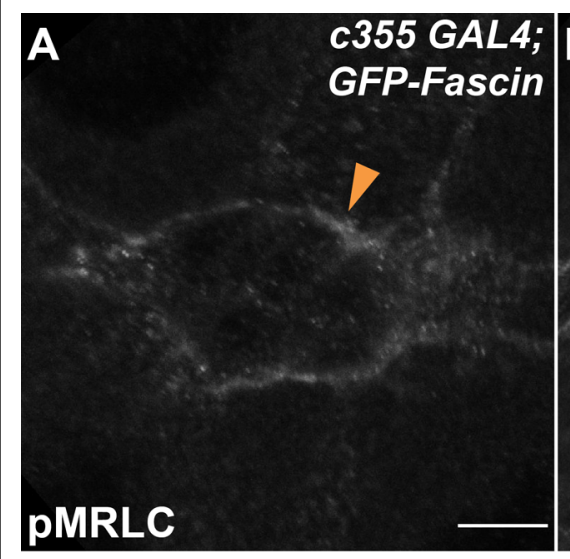

D

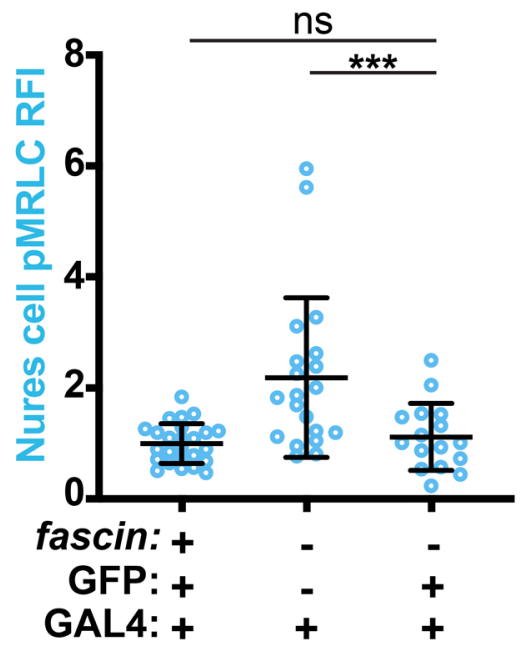

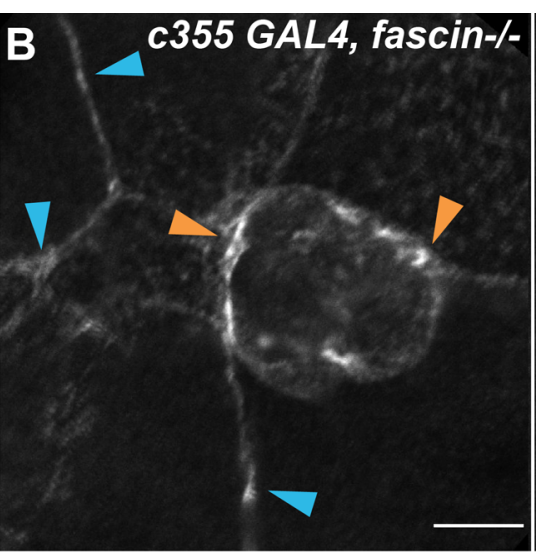

E

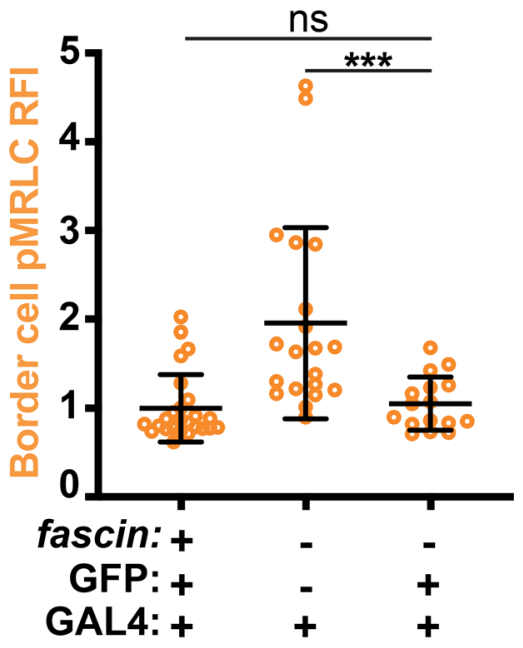

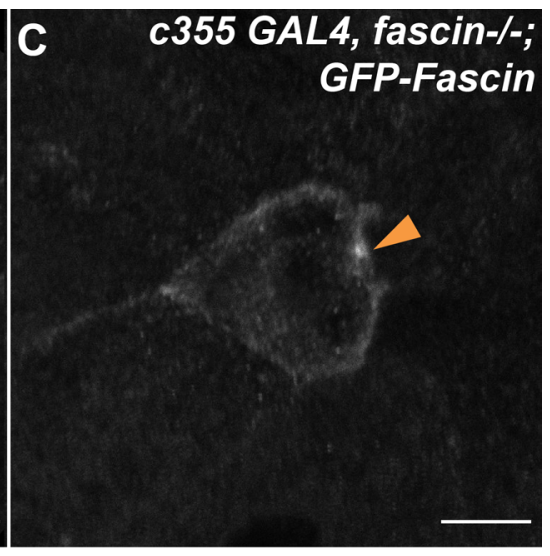

$\mathbf{F}$

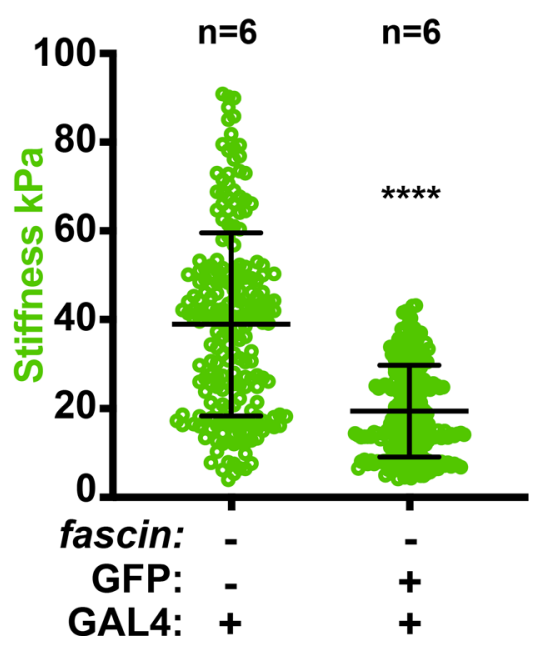

Figure 7. Somatic rescue of Fascin reduces nurse cell Myosin activity and stiffness. (A-C) Maximum projections of 2-4 confocal slices of Stage 9 follicles of the indicated genotypes stained for phospho-MRLC (pMRLC, white). Blue arrows = pMRLC enrichment on surrounding nurse cells. Orange arrows = pMRLC enrichment on border cell cluster. Scale bars $=10 \mu \mathrm{m}$. (A) Somatic GFP-Fascin expression (c355 GAL4/+; UAS-GFP-Fascin/+). (B) fascin

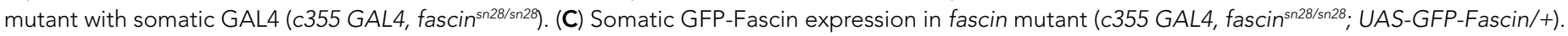
(D, E) Graphs of quantification of pMRLC intensity at the nurse cell membranes (D) and border cell cluster (E) in the indicated genotypes. Each circle represents a follicle. Error bars $=S D$. ns indicates $p>0.05,{ }^{* *} p<0.0001$ (one-way ANOVA with Tukey's multiple comparison test). In $\mathbf{D}$, peak pMRLC intensity was quantified at the nurse cell membranes and normalized to phalloidin staining in the same follicle, three measurements were taken per follicle and averaged. In E, pMRLC intensity on the border cell cluster was quantified and normalized to background staining in the same follicle. (F) Graph of nurse cell stiffness ( $\mathrm{kPa}$ ) of the indicated genotypes as measured by AFM. Each circle represents a single indentation. Error bars $=\mathrm{SD}$. ${ }^{\star \star \star \star} \mathrm{p}<0.0001$ (unpaired t-test). Restoring Fascin expression in the somatic cells of a fascin mutant follicle (C) significantly reduces activated Myosin enrichment on the nurse cell membranes (D) and border cell cluster (E) and reduces nurse cell stiffness by AFM (F) compared to the fascin-null control. All genotypes are listed in Table 1.

The online version of this article includes the following source data and figure supplement(s) for figure 7 :

Source data 1. Source data for Figure 7D, E.

Figure supplement 1. Increasing border cell stiffness through activated Rok increases activated Myosin on the nurse cells.

Figure supplement 1-source data 1. Source data Figure 7-figure supplement 1C, D.

Given the surprising nature of our findings, we next wanted to determine if the border cell regulation of nurse cell stiffness is specific to Fascin or if it is a general principle. To test this idea, we expressed a constitutively active form of Rok (Rok-CAT) in the border cells (c306 GAL4). Rok is one of the kinases that phosphorylates MRLC to activate Myosin. Thus, expressing constitutively active Rok will increase activation of Myosin, which, in turn, will increase cortical tension and therefore the stiffness of the border cells. We find that expression of constitutively active Rok in the border cells significantly increases active MRLC enrichment on both the nurse cell membranes (Figure 7-figure supplement 
$1 \mathrm{~B}$ compared to $1 \mathrm{~A}$, blue arrows, and $\mathrm{C}, \mathrm{p}<0.0001$ ) and the border cell cluster (Figure 7-figure supplement $1 \mathrm{~B}$ compared to $1 \mathrm{~A}$, orange arrows and $\mathrm{D}, \mathrm{p}<0.001$ ). These data suggest that the nurse cells, in general, respond to changes in stiffness of the border cells by altering their own cellular stiffness (Figure 8). This non-autonomous regulation of substrate stiffness by the migratory border cells is an unexpected finding.

\section{Discussion}

Using Drosophila border cell migration as a model, we provide the first evidence that Fascin limits Myosin activity in vivo to control tissue stiffness Figure 8. We find that loss of Fascin significantly increases activated Myosin, and this increase contributes to the border cell migration delays observed in fascin mutant follicles during S9. Our data suggest that Fascin's bundling activity is required to limit Myosin activation, supporting the prior proposed model that Fascin tightly bundles F-actin and precludes Myosin from binding to actin filaments (Elkhatib et alo, 2014). The increased Myosin activity in fascin mutants results in substrate stiffening. Using cell-specific knockdown and rescue experiments, we made the suprising finding that Fascin activity in the border cells is necessary and sufficient to regulate Myosin activity and stiffness of the nurse cells. Thus, Fascin activity within the border cells plays a critical role in controlling the balance of forces between the border cells and their substrate, the nurse cells. We also show that this force balance is not specific to Fascin, as directly altering Myosin activity within the border cells phenocopies knockdown of Fascin in these cells. Together our data uncover that in vivo, collectively migrating cells modulate the stiffness of their substrate to control their own migration (Figure 8).

Multiple lines of evidence support the model that Fascin is a critical regulator of cellular and tissue stiffness. Specifically, loss of Fascin results in increased active pMRLC on both the border cell and nurse cell membranes, altered MRLC-GFP dynamics on the border cell cluster, and increased nurse cell stiffness as measured by AFM (Figures 2 and 3). Interestingly, PMRLC staining and MRLC-GFP time-lapse imaging exhibit distinct patterns (Figure 2). In both wild-type and fascin mutant follicles, the MRLC-GFP regions are shorter in length than PMRLC puncta. We suspect this difference is due to the MRLC-GFP time-lapse imaging capturing a small period of just activated Myosin, whereas fixation and PMRLC staining captures a longer period of activity. For instance, when Fascin is lost the MRLC-GFP puncta have a longer lifetime, this longer period of Myosin activity may be captured as an increased number of shorter pMRLC puncta. The short and numerous PMRLC puncta may also suggest that Myosin activity in the border cells is not appropriately spatially regulated in fascin mutants. These data, in conjunction with our cell-specific RNAi and rescue analyses (Figures 6 and 7 ), reveal that Fascin acts primarily within the border cells to control the stiffness of their substrate, the nurse cells.

Fascin-dependent inhibition of nurse cell Myosin activity and stiffness is essential for on-time border cell migration (Figure 4), raising the question of how Fascin regulates Myosin. Our data supports the previously proposed model that Fascin bundled F-actin prevents Myosin binding to F-actin and thereby, restricts Myosin activity (Elkhatib et alo, 2014). Specifically, we find that expression of the phosphomimetic form of Fascin (S52E), which is unable to bundle F-actin, in fascin mutants fails to both inhibit Myosin activation (Figure 5) or fully restore migration (Figure 5-figure supplement 1). It is important to note that phosphorylated Fascin, and likely phosphomimetic Fascin, also exhibits reduced F-actin binding by in vitro assays (Yamakita et alo, 1996), raising the possibility that Fascin binding to F-actin, without bundling filaments, is sufficient to inhibit Myosin activation. Further experiments are needed to fully elucidate how Fascin limits Myosin activity.

Our discovery that Fascin limits Myosin activity in vivo is unlikely to be restricted to Drosophila. Indeed, both Fascin and Myosin play critical roles during cancer metastasis (Hashimoto et al., 2011; Aguilar-Cuenca et alo, 2014; Ma and Machesky, 2015). Increased Myosin activation and consequently, increased stiffness are a common phenotype observed in cancer cells and their substrate (Tse et al., 2012; Aguilar-Cuenca et al., 2014; van Helvert and Friedl, 2016; Ren et alo, 2021). Increased substrate stiffness promotes migration in a wide range of cancers, suggesting increased Myosin activity can lead to increased cancer metastasis (Aguilar-Cuenca et al., 2014; Emon et al., 2018; Mierke, 2020; Ren et al., 2021). Additionally, Fascin is highly expressed in many types of cancers, notably carcinomas (Hashimoto et al., 2011; Ma and Machesky, 2015). High Fascin expression in these cancers is correlated with increased migration (Grothey et al., 2000; Hashimoto et alo, 2007), invasion (Adams et al., 1999; Minn et al., 2005), and metastasis (Li et al., 2014; Alburquerque-González 


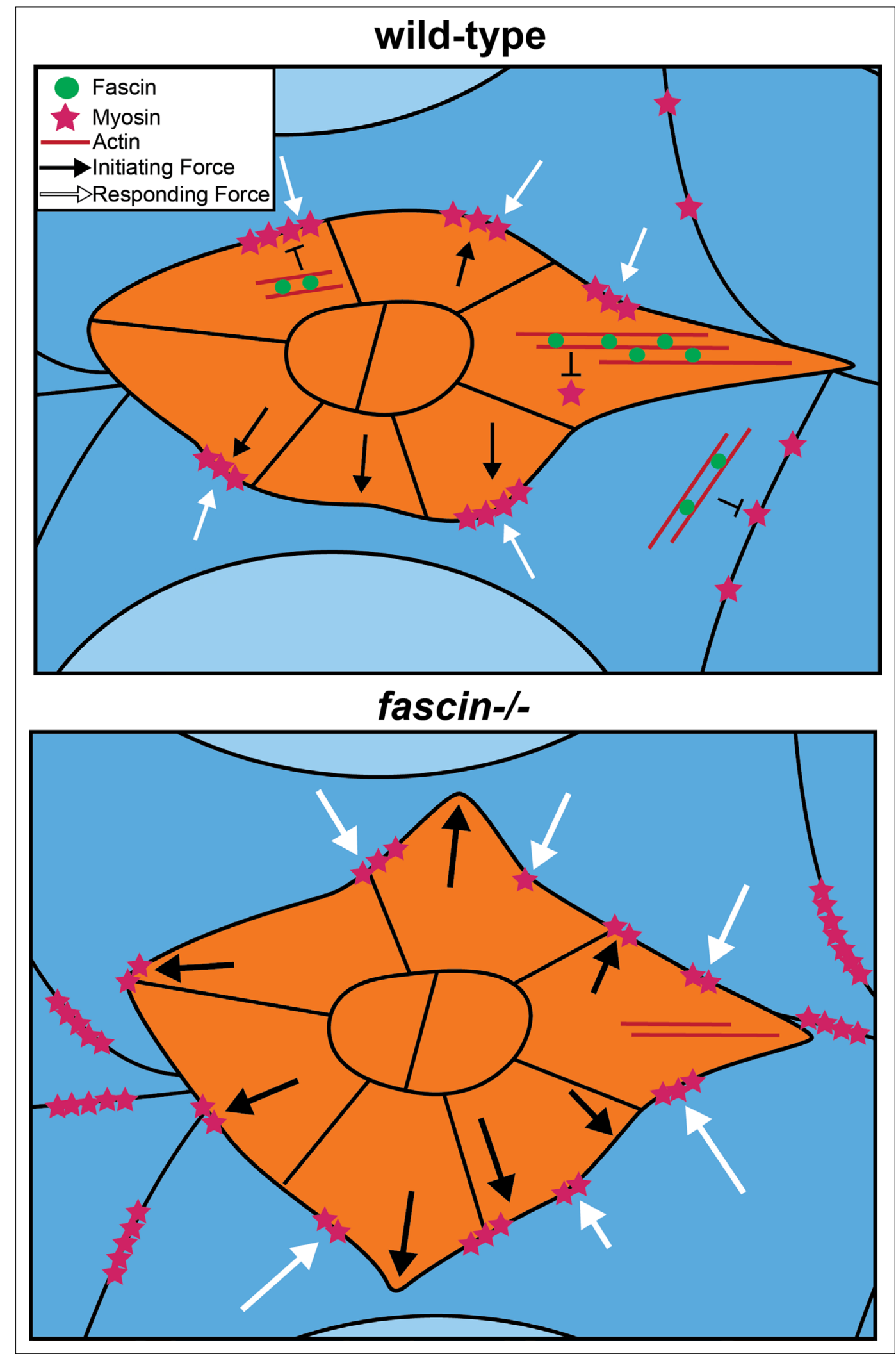

Figure 8. Proposed model for Fascin limiting Myosin activity to control substrate stiffness during border cell migration. In wild-type border cell clusters (orange), Fascin (green circles) bundles F-actin (red lines) to limit Myosin activity (magenta stars) on the border cell cluster and on the nurse cell membranes. Myosin activity in the border cell cluster generates forces (black arrows) that pushes on the nurse cells which results in the nurse cells

Figure 8 continued on next page 
Figure 8 continued

responding with force (white arrows). This balance of forces is required for on-time migration. In fascin mutant follicles, Myosin activity on the border cell cluster is increased, driving increased Myosin activity on the nurse cells. This imbalance of forces between the border cell cluster and the nurse cell substrate impairs border cell migration.

et al., 2020). However, according to our model, increased Fascin would reduce Myosin activity. Our finding that Fascin-dependent bundling is required to limit Myosin activity and substrate stiffness suggests that phosphorylated Fascin may promote cancer metastasis by allowing high Myosin activation and potentially other bundling-independent functions. Supporting this idea, expression of a S39 phosphomimetic form of Fascin, which cannot bundle F-actin, promotes human colon carcinoma migration (Hashimoto et al., 2007), suggesting phosphorylated Fascin could promote cancer metastasis by allowing increased Myosin activation and cell stiffness.

Our finding that phosphomimetic Fascin only partially rescues the migration delay in fascin mutants suggests that non-bundling roles of Fascin also contribute to border cell migration. Indeed, Fascin has many functions besides F-actin bundling, such regulating microtubules (Villari et al., 2015) and acting within the nucleus (Groen et al., 2015). Additionally, S52 phosphorylated Fascin functions as an adaptor for the Linker of the Nucleoskeleton and Cytoskeleton (LINC) Complex (Groen et al., 2015; Jayo et al., 2016). This LINC Complex role of Fascin is required for nuclear shape changes necessary for mammalian single-cell invasive migration (Jayo et al., 2016), raising the idea that Fascin may be similarly required for the invasion of the border cells between the nurse cells. Further experiments are needed to understand how the different functions of Fascin are coordinated to promote migration.

Our results suggest that increased stiffness in the border cell cluster affects the stiffness of its substrate, the nurse cells (Figures 6 and 7). This non-autonomous function of the border cells in altering the stiffness of the nurse cells was unexpected, as previous data suggested the nurse cells exert force on the border cells and the border cells respond to this force (Aranjuez et al., 2016). This balance of forces is necessary to promote the migration of the cluster through the tightly packed nurse cells (Aranjuez et al., 2016). Specifically, a previous study observed that overexpression of a Rho GEF in the nurse cells, which both increased Myosin activation and caused the nurse cells to change their shape and become more circular, ultimately impairs border cell migration (Aranjuez et al., 2016). As we do not observe any obvious changes in nurse cell shape when Fascin is lost or knocked down in the nurse cells, it may be that loss of Fascin does not cause a severe enough change in nurse cell Myosin activity and cell stiffness to cause the border cell cluster to respond. Instead, our data suggest that the border cells play a larger role in this balance of forces by exerting force on the nurse cells to control nurse cell stiffness. This interaction could potentially allow the border cell cluster to stiffen the nurse cells as the cluster migrates. Interestingly, in the context of cancer cell migration, a stiffer substrate often promotes cell migration (Parekh and Weaver, 2016; Oakes, 2018; Ren et al., 2021). Further, there is growing evidence that one means of directing migration is a gradient of substrate stiffness, such that cells move from softer to stiffer substrates; this is termed durotaxis (Sunyer and Trepat, 2020; Shellard and Mayor, 2021). Indeed, durotaxis has emerged as a property of collectively migrating cells. Specifically, it has been suggested that clusters of migrating cells are better able to sense differences in stiffness and respond more effectively (Martinez et al., 2016; Sunyer et al., 2016). Therefore, it is tempting to speculate that the border cells exert force on the nurse cells to stiffen them to aid in migration.

A key remaining question is whether border cells regulates substrate stiffness in a spatial and/ or temporal manner. Specifically, do the border cells push on the nurse cells as they are migrating, driving a wave of local Myosin activation and stiffening of the nurse cell substrate? In other systems, such local stiffening appears to be cell-type and context specific, and can occur at the front or back of the migrating cells (Doyle et al., 2021). Based on both our fixed- and live-imaging of Myosin activity, we believe the stiffening of the nurse cell substrate occurs on all sides of the border cell cluster. This phenotype is consistent in wild-type and fascin-null follicles with fascin-null follicles displaying an overall increase in pMRLC. However, our current means of assessing Myosin activity and cellular stiffness lack the resolution necessary to determine how Myosin activation and changes in stiffness propagate through the nurse cells. Future studies using tools that allow Myosin activity in the border cells to be distinguished from that in its nurse cell substrate, in conjunction with higher resolution, rapid, non-photobleaching microscopy approaches, and cell-specific means of assessing individual 
nurse cell stiffness, such as laser ablation recoil velocity assessments, are need to uncover the detailed dynamics of how the balance of forces between the border cells and their substrate, the nurse cells, drives collective cell migration.

It remains unclear how Myosin activity at the cell cortex is connected to cellular adhesions in the border cells. Prior work indicates that the border cells migrate directly on the nurse cells, as there is little to no ECM present (Medioni and Noselli, 2005), and thus, Integrin-based ECM adhesions are not critical for border cell migration (Dinkins et al., 2008; Llense and Martín-Blanco, 2008; Montell et al., 2012). Instead, border cells may utilize E-Cadherin based adhesions (Niewiadomska et al., 1999; Cai et al., 2014) or perhaps uncharacterized means to drive migration. Thus, additional work is needed to determine the cellular connections mediating Myosin-dependent force transmission between the border cells and the nurse cells.

While it is clear that the balance of forces between the border cells and the nurse cells is critical for border cell migration, the mechanisms by which force imbalances impair migration remain poorly understood. We speculate that the increased Myosin activity in fascin mutants delays migration by impacting delamination and protrusion dynamics. We previously found that Fascin is required for on-time delamination of the border cell cluster from the follicular epithelium and for restricting the number and location of protrusions to the leading edge of the border cell cluster (Lamb et al., 2020). Similarly, both loss and constitutive activation of Myosin within the border cells delays delamination and causes excessive and misdirected protrusions (Majumder et al., 2012; Aranjuez et al., 2016; Mishra et al., 2019). These data suggest that it is not only the level of Myosin activity but is ability to cycle between active and inactive states that contributes to these two aspects of border cell migration. Based on our data, we suspect altering Myosin activity in the border cells ultimately changes the stiffness of the nurse cells. Too little activation of Myosin would result in a soft substrate and too much would result in a stiff substrate. Such changes in substrate stiffness could alter the polarization of the cluster, resulting in mislocalized and increased protrusions which not only delay migration but impair delamination. Supporting this idea, Myosin regulates active Rac polarization within the border cells (Mishra et al., 2019). Rac activation is highest in the leading cell of the border cell cluster and is require to generate forward directed protrusions (Fulga and Rørth, 2002; Bianco et al., 2007; Mishra et al., 2019). Increased Myosin activation in the border cell cluster disrupts this polarization, resulting in mislocalized protrusions (Mishra et al., 2019). This loss of polarization could function cell-autonomously, but, based on our data, it may also increase nurse cell stiffness. Such increased substrate stiffness could impair delamination and cause mislocalized protrusions by physically altering the topography of the nurse cells, which has recently been shown to be critical for border cell migration and forward directed protrusions (Dai et al., 2020). Additionally, increased substrate stiffness could disrupt durotactic signaling or alter the diffusion of the ligands directing migration. Thus, Fascin's role in limiting Myosin activation likely contributes to the delayed delamination and aberrant mislocalized protrusions observed during border cell migration in fascin-null follicles.

The mechanical communication between migrating cells and their substrate is a growing area of research. The overarching premise in the field has been that substrate stiffness regulates the mechanical properties of the migrating cells and thereby, alters their ability to migrate. For example, in a model of breast cancer cell migration, high substrate stiffness promotes migration (Ren et al., 2021). Additionally during zebrafish development, the underlying mesoderm must stiffen to induce the epithelial to mesenchymal transition (EMT) and migration of the neural crest cells (Barriga et al., 2018). Together these studies highlight the current paradigm that substrate stiffness is the driving force that regulates the migrating cells to control their migration. However, the roles of the migrating cells in controlling their substrate stiffness are less understood. Numerous studies support that migrating cells can degrade surrounding ECM, creating paths for easier migration (for example: Wolf et al., 2007); such changes likely decrease substrate stiffness in the local environment. Migrating cells also pull on their local environment, applying a strain on the environment and aligning ECM fibers, which ultimately causes a local increase in substrate stiffness (Hall et alo, 2016; van Helvert and Friedl, 2016). Notably, collectively migrating cells exert $4 \times$ more force on their environment than single cells (van Helvert and Friedl, 2016). These studies indicate migrating cells can, at least locally, influence the stiffness of their substrate. This increase in substrate stiffness promotes cell migration, increasing migratory cell force generation in a process termed mechanoreciprocity (van Helvert et al., 2018). Whether migrating cells control substrate and underlying tissue stiffness in native, physiological contexts, and whether local stiffness changes are 
propagated through the tissue remain poorly understood. Supporting that this may occur, cancer cells drive stromal changes, including increased fibrosis which stiffens the tissue (van Helvert et al., 2018; Chandler et alo, 2019; Piersma et al., 2020). These changes have been proposed as potential mechanism by which cancer cells drive their own invasion and make environments supportive of metastatic colonization (Cox and Erler, 2014). Our finding that Fascin activity in the migrating border cells controls substrate stiffness to promote migration positions Drosophila border cell migration as a robust system to uncover the mechanisms controlling this means of force balance.

Here, we propose that migrating cells modulate their own stiffness to regulate substrate stiffness. Our findings suggest that during collective cell migrations, such as those during development and cancer metastasis, the migrating cells apply force to induce the stiffening of their substrate, this results in a reciprocal mechanical communication between the migrating cells and their substrate which drives migration. Further, we demonstrate that Fascin, an F-actin bundling protein, limits the activity of Myosin in the migrating cells to regulate substrate stiffness. Overall, our findings expand our understanding of the mechanical relationship between migrating cells and their substrate, shifting the paradigm in the field from the substrate controlling migrating cell stiffness and thereby, migration, to the migrating cells playing a key role in altering their environment and substrate stiffness to promote their own migration.

\section{Materials and methods}

Key resources table

\begin{tabular}{|c|c|c|c|c|}
\hline $\begin{array}{l}\text { Reagent type (species) or } \\
\text { resource }\end{array}$ & Designation & Source or reference & Identifiers & $\begin{array}{l}\text { Additional } \\
\text { information }\end{array}$ \\
\hline $\begin{array}{l}\text { Genetic reagent (Drosophila } \\
\text { melanogaster) }\end{array}$ & $y^{1} w^{1}$ & $\begin{array}{l}\text { Bloomington Drosophila Stock } \\
\text { Center }\end{array}$ & $\begin{array}{l}\text { BDSC Cat \# } 1495 \\
\text { RRID:BDSC_1495 }\end{array}$ & \\
\hline $\begin{array}{l}\text { Genetic reagent ( } D . \\
\text { melanogaster) }\end{array}$ & fascin $^{\text {sn28/sn28 }}$ & other & FBgn0003447 & from J. Zanet \\
\hline $\begin{array}{l}\text { Genetic reagent ( } D . \\
\text { melanogaster) }\end{array}$ & fTRG sqh & $\begin{array}{l}\text { Vienna Drosophila Resource } \\
\text { Center }\end{array}$ & VRDC Cat \# 318,484 & fTRG 10075 \\
\hline $\begin{array}{l}\text { Genetic reagent ( } D . \\
\text { melanogaster) }\end{array}$ & oskar GAL4 (2) & $\begin{array}{l}\text { Bloomington Drosophila Stock } \\
\text { Center }\end{array}$ & $\begin{array}{l}\text { BDSC Cat \# } 44,241 \\
\text { RRID:BDSC_44241 }\end{array}$ & Anne Ephrussi \\
\hline $\begin{array}{l}\text { Genetic reagent ( } D . \\
\text { melanogaster) }\end{array}$ & UAS-sqh RNAi & $\begin{array}{l}\text { Bloomington Drosophila Stock } \\
\text { Center }\end{array}$ & $\begin{array}{l}\text { BDSC Cat \# 33,892 } \\
\text { RRID:BDSC_33892 }\end{array}$ & \\
\hline $\begin{array}{l}\text { Genetic reagent ( } D . \\
\text { melanogaster) }\end{array}$ & $\operatorname{actin} 5$ c GAL4 & $\begin{array}{l}\text { Bloomington Drosophila Stock } \\
\text { Center }\end{array}$ & $\begin{array}{l}\text { BDSC Cat \# 8,807 } \\
\text { RRID:BDSC_8807 }\end{array}$ & \\
\hline $\begin{array}{l}\text { Genetic reagent ( } D . \\
\text { melanogaster) }\end{array}$ & UAS-GFP-Fascin & $\begin{array}{l}\text { Zanet et al., } 2009 \text { PMID: } \\
19592575\end{array}$ & & from J. Zanet \\
\hline $\begin{array}{l}\text { Genetic reagent ( } D . \\
\text { melanogaster) }\end{array}$ & UAS-GFP-Fascin-S52E & $\begin{array}{l}\text { Zanet et al., } 2009 \text { PMID: } \\
19592575\end{array}$ & & from J. Zanet \\
\hline $\begin{array}{l}\text { Genetic reagent ( } D . \\
\text { melanogaster) }\end{array}$ & UAS-Fascin-RNAi & $\begin{array}{l}\text { Bloomington Drosophila Stock } \\
\text { Center }\end{array}$ & $\begin{array}{l}\text { BDSC Cat \# } 42,615 \\
\text { RRID:BDSC_42615 }\end{array}$ & \\
\hline $\begin{array}{l}\text { Genetic reagent ( } D . \\
\text { melanogaster) }\end{array}$ & mat $\alpha$ GAL4 & $\begin{array}{l}\text { Bloomington Drosophila Stock } \\
\text { Center }\end{array}$ & $\begin{array}{l}\text { BDSC Cat \# 7,063 } \\
\text { RRID:BDSC_7063 }\end{array}$ & \\
\hline $\begin{array}{l}\text { Genetic reagent ( } D . \\
\text { melanogaster) }\end{array}$ & c355 GAL4 & $\begin{array}{l}\text { Bloomington Drosophila Stock } \\
\text { Center }\end{array}$ & $\begin{array}{l}\text { BDSC Cat \# 3,750 } \\
\text { RRID:BDSC_3750 }\end{array}$ & \\
\hline $\begin{array}{l}\text { Genetic reagent ( } D . \\
\text { melanogaster) }\end{array}$ & c306 GAL4 & $\begin{array}{l}\text { Bloomington Drosophila Stock } \\
\text { Center }\end{array}$ & $\begin{array}{l}\text { BDSC Cat \# 3,743 } \\
\text { RRID:BDSC_3743 }\end{array}$ & \\
\hline $\begin{array}{l}\text { Genetic reagent ( } D . \\
\text { melanogaster) }\end{array}$ & UAS-Rok-CAT & $\begin{array}{l}\text { Bloomington Drosophila Stock } \\
\text { Center }\end{array}$ & $\begin{array}{l}\text { BDSC Cat \# 6,669 } \\
\text { RRID:BDSC_6669 }\end{array}$ & \\
\hline Antibody & $\begin{array}{l}\text { rabbit polyclonal anti-Phospho- } \\
\text { Myosin Light Chain } 2 \text { (Ser19) }\end{array}$ & Cell Signaling & $\begin{array}{l}\text { \#3,671 } \\
\text { RRID:AB_330248 }\end{array}$ & $(1: 100)$ \\
\hline Antibody & $\begin{array}{l}\text { mouse monoclonal anti-Hu li tai } \\
\text { shao (Hts) }\end{array}$ & $\begin{array}{l}\text { Developmental Studies } \\
\text { Hybridoma Bank }\end{array}$ & $\begin{array}{l}\text { 1B1 } \\
\text { RRID:AB_528070 }\end{array}$ & $(1: 50)$ \\
\hline
\end{tabular}

Continued on next page 
Continued

\begin{tabular}{|c|c|c|c|c|}
\hline $\begin{array}{l}\text { Reagent type (species) or } \\
\text { resource }\end{array}$ & Designation & Source or reference & Identifiers & $\begin{array}{l}\text { Additional } \\
\text { information }\end{array}$ \\
\hline Antibody & mouse monoclonal anti-Fasciclin III & $\begin{array}{l}\text { Developmental Studies } \\
\text { Hybridoma Bank }\end{array}$ & $\begin{array}{l}\text { 7G10 } \\
\text { RRID:AB_528238 }\end{array}$ & $(1: 50)$ \\
\hline Antibody & rat monoclonal anti-Vasa & $\begin{array}{l}\text { Developmental Studies } \\
\text { Hybridoma Bank }\end{array}$ & RRID:AB_760351 & $(1: 100)$ \\
\hline Antibody & rabbit polyclonal anti-Zipper & $\begin{array}{l}\text { Wheatley et al., } 1995 \text { PMID: } \\
7601006\end{array}$ & & $(1: 10000)$ \\
\hline Antibody & rabbit polyclonal anti-GFP & Torrey Pines Biolabs, Inc & $\begin{array}{l}\text { TP401 } \\
\text { RRID:AB_10013661 }\end{array}$ & $(1: 2000)$ \\
\hline Antibody & goat polyclonal anti-GFP & $\begin{array}{l}\text { Fitzgerald Industries } \\
\text { International }\end{array}$ & $\begin{array}{l}\text { 70R-GG001 } \\
\text { RRID:AB_1286216 }\end{array}$ & $(1: 2000)$ \\
\hline Antibody & $\begin{array}{l}\text { goat polyclonal Alexa Fluor } 488 \text { anti- } \\
\text { mouse }\end{array}$ & Thermo Fischer Scientific & $\begin{array}{l}\text { A-11001 } \\
\text { RRID:AB_2534069 }\end{array}$ & $(1: 500)$ \\
\hline Antibody & $\begin{array}{l}\text { goat polyclonal Alexa Fluor } 568 \text { anti- } \\
\text { mouse }\end{array}$ & Thermo Fischer Scientific & $\begin{array}{l}\text { A-11004 } \\
\text { RRID:AB_2534072 }\end{array}$ & $(1: 500)$ \\
\hline Antibody & $\begin{array}{l}\text { goat polyclonal Alexa Fluor } 488 \text { anti- } \\
\text { rabbit }\end{array}$ & Thermo Fischer Scientific & $\begin{array}{l}\text { A-11034 } \\
\text { RRID:AB_2576217 }\end{array}$ & $(1: 500)$ \\
\hline Antibody & $\begin{array}{l}\text { goat polyclonal Alexa Fluor } 568 \text { anti- } \\
\text { rabbit }\end{array}$ & Thermo Fischer Scientific & $\begin{array}{l}\text { A-11036 } \\
\text { RRID:AB_10563566 }\end{array}$ & $(1: 500)$ \\
\hline Antibody & $\begin{array}{l}\text { donkey polyclonal Alexa Fluor } 488 \\
\text { anti-goat }\end{array}$ & Thermo Fischer Scientific & $\begin{array}{l}\text { A-11055 } \\
\text { RRID:AB_2534102 }\end{array}$ & $(1: 500)$ \\
\hline Antibody & $\begin{array}{l}\text { Peroxidase-AffiniPure goat } \\
\text { polyclonal anti-rabbit }\end{array}$ & $\begin{array}{l}\text { Jackson ImmunoResearch } \\
\text { Laboratories }\end{array}$ & $\begin{array}{l}\text { 111-035-003 } \\
\text { RRID:AB_2313567 }\end{array}$ & $(1: 5000)$ \\
\hline Antibody & $\begin{array}{l}\text { Peroxidase-AffiniPure goat } \\
\text { polyclonal anti-rat }\end{array}$ & $\begin{array}{l}\text { Jackson ImmunoResearch } \\
\text { Laboratories }\end{array}$ & $\begin{array}{l}\text { 112-035-003 } \\
\text { RRID:AB_2338128 }\end{array}$ & $(1: 5000)$ \\
\hline Chemical compound, drug & $\begin{array}{l}\text { 4',6-Diamidino-2-phenylindole } \\
\text { (DAPI) }\end{array}$ & Millipore Sigma & D9542 & $5 \mathrm{mg} / \mathrm{ml}$ \\
\hline Chemical compound, drug & Alexa Flour 568 or 647 Phalloidin & Thermo Fischer Scientific & $\mathrm{A} 12380$ or $\mathrm{A} 22287$ & $(1: 250$ or $1: 500)$ \\
\hline Chemical compound, drug & Y-27632 & Millipore Sigma & Y0503 & $200 \mu \mathrm{M}$ \\
\hline Software, algorithm & FIJI & $\begin{array}{l}\text { Schindelin et al., } 2012 \\
\text { PMID:22743772 }\end{array}$ & RRID:SCR_002285 & \\
\hline Software, algorithm & Prism 8 and 9 & https://www.graphpad.com/ & RRID:SCR_002798 & \\
\hline Software, algorithm & Adobe Photoshop CC & https://ww.adobe.com/ & RRID:SCR_014199 & \\
\hline Software, algorithm & Adobe Illustrator CC 25.2.3 & https://ww.adobe.com/ & RRID:SCR_010279 & \\
\hline Software, algorithm & LAS AS SPE Core & Leica & & \\
\hline Software, algorithm & ZEN Axio Observer.Z1 & Zeiss & & \\
\hline
\end{tabular}

\section{Fly stocks}

Fly stocks were maintained on cornmeal/agar/yeast food at $21^{\circ} \mathrm{C}$, except where noted. Before immunofluorescence staining and live imaging, flies were fed wet yeast paste daily for 2-4 days. Unless otherwise noted, yw was used as the wild-type control. The following stocks were obtained from the Bloomington Stock Center (Bloomington, IN): mat $\alpha$ GAL4 (third chromosome), c355 GAL4, c306 GAL4, actin5C GAL4, UASp-RNAi-Fascin (TRiP.HMS02450), UASp-Sqh-RNAi (TRiP.HMS00437), and UASp-Rok-CAT. The fTRG sqh stock was obtained from the Vienna Drosophila Resource Center. The

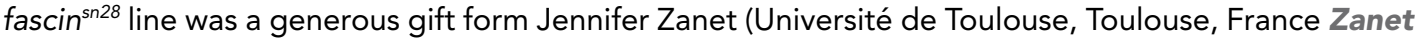
et al., 2012), the oskar GAL4 line (second chromosome) was a generous gift from Anne Ephrussi (European Molecular Biology Laboratory, Heidelber, Germany Telley et al., 2012), and the UASpGFP-Fascin and UASp-GFP-Fascin-S52E lines were a generous gift from Francois Payre (Université de Toulouse, Toulouse, France Zanet et al., 2009). For germline expression during S9, either mat $\alpha$ GAL4 or oskar GAL4 were utilized interchangeably. Expression of UASp-RNAi-Fascin was achieved 
by crossing to mat $\alpha$ GAL4, c355 GAL4, and c306 GAL4, maintaining crosses at $25^{\circ} \mathrm{C}$ and progeny at $29^{\circ} \mathrm{C}$ for 3 days. Expression of UASp-Sqh-RNAi was achieved by crossing to oskar GAL4, maintaining crosses at $25{ }^{\circ} \mathrm{C}$ and progeny at $29{ }^{\circ} \mathrm{C}$ for 3 days. The sn28, c355 GAL4 flies were generated previously (Lamb et al., 2020). Expression of UASp-GFP-Fascin or UASp-GFP-Fascin-S52E was achieved by crossing to actin5C GAL4, crosses were maintained at $25^{\circ} \mathrm{C}$ and progeny at $29^{\circ} \mathrm{C}$ for 2 days. The specific genotypes for each experiment are listed in Table 1.

\section{Immunofluorescence}

Whole-mount Drosophila ovary samples (approximately five flies per experiment) were dissected into Grace's insect media (Lonza, Walkersville, MD) and fixed for $10 \mathrm{~min}$ at room temperature in 4 \% paraformaldehyde in Grace's insect media. Briefly, samples were blocked using antibody wash (1 X phosphatebuffered saline, $0.1 \%$ Triton X-100, and $0.1 \%$ bovine serum albumin) six times for 10 min each. Primary antibodies were diluted with antibody wash and incubated overnight at $4{ }^{\circ} \mathrm{C}$. The following primary antibodies were obtained from the Developmental Studies Hybridoma Bank (DSHB) developed under the auspices of the National Institute of Child Health and Human Development and maintained by the Department of Biology, University of lowa (lowa City, IA): mouse anti-Hts 1:50 (1B1, Lipshitz, HD Zaccai and Lipshitz, 1996), mouse anti-Faslll 1:50 (7G10, Goodman, C Patel et al., 1987); mouse antiFascin 1:20 (sn7c, Cooley, L Cant et alo, 1994). Additionally, the following primary antibody was used: rabbit anti-GFP 1:2000 (pre-absorbed on yw ovaries at 1:20 and used at 1:100; Torrey Pines Biolabs, Inc, Secaucus, NJ). After six washes in Triton antibody wash (10 min each), secondary antibodies were incubated overnight at $4{ }^{\circ} \mathrm{C}$ or for $\sim 4 \mathrm{hr}$ at room temperature. The following secondary antibodies were used at 1:500: AlexaFluor (AF)488::goat anti-mouse, AF568::goat anti-mouse, AF488::goat anti-rabbit, AF568::goat anti-rabbit (Thermo Fischer Scientific). AF647-, or AF568-conjugated phalloidin (Thermo Fischer Scientific) was included with primary and secondary antibodies at a concentration of 1:250. After six washes in antibody wash (10 minutes each), 4',6-diamidino-2-phenylindole (DAPI, $5 \mathrm{mg} / \mathrm{ml}$ ) staining was performed at a concentration of 1:5,000 in $1 \mathrm{X}$ PBS for 10 minutes at room temperature. Ovaries were mounted in $1 \mathrm{mg} / \mathrm{ml}$ phenylenediamine in 50 \% glycerol, pH 9 (Platt and Michael, 1983). All experiments were performed a minimum of three independent times.

Active-MRLC staining was performed using a modified protocol provided by Jocelyn McDonald (Majumder et al., 2012; Aranjuez et alı, 2016). Briefly, ovaries were fixed for $20 \mathrm{~min}$ at room temperature in $8 \%$ paraformaldehyde in $1 \mathrm{X}$ phosphate-buffered saline (PBS) and $0.5 \%$ Triton X-100. Samples were blocked by incubating in Triton antibody wash (1XPBS, $0.5 \%$ Triton X-100, and $5 \%$ bovine serum albumin) for $30 \mathrm{~min}$. Primary antibodies were incubated for $48 \mathrm{hr}$ at $4{ }^{\circ} \mathrm{C}$. The rabbit anti-pMRLC (S19; Cell Signaling, Davers, MA) was diluted 1:100 in Triton antibody wash. Anti-Fascin (sn7c, 1:20) was sometimes added to the primary antibody solution to differentiate between wildtype and fascin-null follicles in the same sample or to confirm Fascin RNAi knockdown. In other cases, anti-Hts (1B1, 1:50) and anti-FasIII (7G10, 1:50) were added to the primary antibody solution to allow for visualization of the border cell cluster boundaries. After six washes in Triton antibody wash (10 min each), the secondary antibodies were diluted 1:500 in Triton antibody wash and incubated overnight at $4{ }^{\circ} \mathrm{C}$. Alexa Fluor 647-phalloidin (Invitrogen, Life Technologies, Grand Island, NY) was included with both primary and secondary antibodies at a concentration of 1:250; this allowed for visualization of the border cell cluster boundaries. Samples were washed six times in Triton antibody wash (10 min each) and the stained with DAPI and mounted as described above.

\section{Image acquisition and processing}

Microscope images of fixed Drosophila follicles were obtained using LAS AS SPE Core software on a Leica TCS SPE mounted on a Leica DM2500 using an ACS APO 20 x/0.60 IMM CORR -/D objective (Leica Microsystems, Buffalo Grove, IL) or using Zen software on a Zeiss 700 LSM mounted on an Axio Observer.Z1 using a Plan-Apochromat 20 x/0.8 working distance (WD) $=0.55$ M27 or a EC-Plan-NeoFluar 40 x/1.3 oil objective (Carl Zeiss Microscopy, Thornwood, NY). Maximum projections (two to four confocal slices), merged images, rotations, and cropping were performed using ImageJ software (Abramoff et al., 2004). S9 follicles were identified during fixed imaging by the size of the follicle $(\sim 150-250 \mu \mathrm{m})$, the position and morphology of the outer follicle cells, and presence of a border cell cluster. The beginning of S10 was defined as when the anterior most outer follicle cells reached the nurse cell-oocyte boundary and flattened. 
Table 1. Genotype by figures.

List of genotype show in the figures.

\begin{tabular}{|c|c|c|}
\hline Figure & Panel & Genotype \\
\hline & $\mathrm{B}$ & $y w$ \\
\hline \multirow[t]{8}{*}{ Figure 1} & C & fascin $^{\mathrm{sn} 28 / \operatorname{sn} 28}$ \\
\hline & $A-A "$ & $y w$ \\
\hline & B-B" & fascin $^{\text {sn28/sn28 }}$ \\
\hline & & $y w$ \\
\hline & $\mathrm{C}-\mathrm{F}$ & fascin $^{\text {sn28/sn28 }}$ \\
\hline & G-G'"' & $\operatorname{fascin}^{\mathrm{sn} 28} /+;+/$ sqh-GFP \\
\hline & $\mathrm{H}-\mathrm{H}^{\prime \prime \prime}$ & fascin $\operatorname{sn}^{\text {s28/sn28; }}+$ /sqh-GFP \\
\hline & & fascin $\operatorname{sn}^{\operatorname{si}} /+;+$ sqh-GFP \\
\hline \multirow[t]{3}{*}{ Figure 2} & । & $\operatorname{fascin}^{\mathrm{s} 28 / \mathrm{sn} 28} ;+/$ sqh-GFP \\
\hline & $A-B$ & fascin ${ }^{\text {sn28/sn28 }}$ \\
\hline & & $y w$ \\
\hline \multirow[t]{3}{*}{ Figure 2-figure supplement 1} & $\mathrm{C}-\mathrm{F}$ & fascin ${ }^{\text {sn28/sn28 }}$ \\
\hline & $\mathrm{C}$ & $y w$ \\
\hline & & $y w$ \\
\hline \multirow[t]{10}{*}{ Figure 3} & $\mathrm{D}$ & fascin ${ }^{\text {sn28/sn28 }}$ \\
\hline & $\mathrm{B}$ & $y w$ \\
\hline & C-D & $\operatorname{fascin}^{\operatorname{sn} 28 / \operatorname{sn} 28}$ \\
\hline & $E$ & $\operatorname{fascin}^{\mathrm{sn} 28 / \text { sn28; }}$ oskar GAL4 (2)/+ \\
\hline & $\mathrm{F}$ & fascin sn28/sn28; oskar GAL4 (2)/UAS-sqh-RNAi \\
\hline & & $y w$ \\
\hline & G & fascin $^{\text {sn28/sn28 }}$ \\
\hline & & oskar GAL4 (2)/+ \\
\hline & & oskar GAL4 (2)/UAS-sqh-RNAi \\
\hline & & 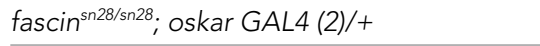 \\
\hline Figure 4 & $\mathrm{H}$ & fascin ${ }^{\text {sn28/sn28; }}$ oskar GAL4 (2)/UAS-sqh-RNAi \\
\hline \multirow[t]{6}{*}{ Figure 4-figure supplement 1} & & $y w$ \\
\hline & $A-B$ & $\operatorname{fascin}^{\mathrm{sn} 28 / \mathrm{sn} 28}$ \\
\hline & C-D & oskar GAL4 (2)/+ \\
\hline & & oskar GAL4 (2)/UAS-sqh-RNAi \\
\hline & & 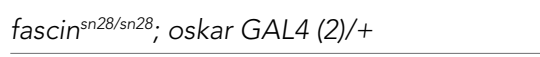 \\
\hline & & fascin ${ }^{\text {sn28/sn28; }}$ oskar GAL4 (2)/UAS-sqh-RNAi \\
\hline
\end{tabular}

Table 1 continued on next page 
Table 1 continued

\begin{tabular}{|c|c|c|}
\hline Figure & Panel & Genotype \\
\hline \multirow[b]{7}{*}{ Figure 5} & A & fascin ${ }^{\text {sn28/sn28; }}$ actin 5c GAL4/+ \\
\hline & $\mathrm{B}$ & fascin $^{\text {sn28/sn28; }}$ actin 5c GAL4/UAS-GFP-Fascin \\
\hline & C & fascin $^{\text {sn28/sn28; }}$ actin 5c GAL4/UAS-GFP-Fascin-S52E \\
\hline & & actin $5 c$ GAL4/+ \\
\hline & & fascin $^{\text {sn28/sn28; }}$ actin 5c GAL4/+ \\
\hline & & fascin $^{\text {nn28/sn28; }}$; actin 5c GAL4/UAS-GFP-Fascin \\
\hline & D-E & fascin ${ }^{\mathrm{sn} 28 / \mathrm{sn} 28}$; actin 5c GAL4/UAS-GFP-Fascin-S52E \\
\hline \multirow[b]{6}{*}{ Figure 5-figure supplement 1} & A & fascin $^{\text {sn28/sn28; }}$ actin 5c GAL4/UAS-GFP-Fascin \\
\hline & B & fascin ${ }^{\text {sn28/sn28; }}$ actin 5c GAL4/UAS-GFP-Fascin-S52E \\
\hline & & actin $5 c$ GAL4/+ \\
\hline & & fascin ${ }^{\text {sn28/sn28; }}$ actin 5c GAL4/+ \\
\hline & & fascin $^{\text {sn28/sn28; }}$ actin 5c GAL4/UAS-GFP-Fascin \\
\hline & C & fascin ${ }^{\text {sn28/sn28; }}$ actin 5c GAL4/UAS-GFP-Fascin-S52E \\
\hline \multirow[b]{8}{*}{ Figure 6} & $\mathrm{~B}$ & +/UAS-Fascin-RNAi (3) \\
\hline & $\mathrm{C}$ & mata GAL4 (3)/UAS-Fascin-RNAi (3) \\
\hline & $\mathrm{D}$ & c355 GAL4/+; +/UAS-Fascin-RNAi (3) \\
\hline & $\mathrm{E}$ & c306 GAL4/+; +/UAS-Fascin-RNAi (3) \\
\hline & & +/UAS-Fascin-RNAi (3) \\
\hline & & mata GAL4 (3)/UAS-Fascin-RNAi (3) \\
\hline & & c355 GAL4/+; +/UAS-Fascin-RNAi (3) \\
\hline & $\mathrm{F}-\mathrm{H}$ & c306 GAL4/+; +/UAS-Fascin-RNAi (3) \\
\hline \multirow[b]{8}{*}{ Figure 7} & A & c355 GAL4/+; +/UAS-GFP-Fascin \\
\hline & $\mathrm{B}$ & c355 GAL4, fascin sn28/sn28 \\
\hline & $\mathrm{C}$ & c355 GAL4, fascin ${ }^{\text {sn28/sn28; }}$ +/UAS-GFP-Fascin \\
\hline & & c355 GAL4/+; +/UAS-GFP-Fascin \\
\hline & & c355 GAL4, fascin ${ }^{\text {sn28/sn28 }}$ \\
\hline & $\mathrm{D}-\mathrm{E}$ & c355 GAL4, fascin sn28/sn28; +/UAS-GFP-Fascin \\
\hline & & c355 GAL4, fascin ${ }^{\text {sn28/sn28 }}$ \\
\hline & $\mathrm{F}$ & c355 GAL4, fascin sn28/sn28; +/UAS-GFP-Fascin \\
\hline \multirow[b]{5}{*}{ Figure 7-figure supplement 1} & A & c306 GAL4/+ \\
\hline & B & c306 GAL4/+; +/UAS-Rok-CAT \\
\hline & & c306 GAL4/+ \\
\hline & & +/UAS-Rok-CAT \\
\hline & C-D & c306 GAL4/+; +/UAS-Rok-CAT \\
\hline \multicolumn{2}{|l|}{ Video 1} & $\operatorname{fascin}^{\operatorname{sn} 28} /+;+$ sqh-GFP \\
\hline \multicolumn{2}{|l|}{ Video 2} & $\operatorname{fascin}^{\operatorname{sn} 28 / \mathrm{sn} 28} ;+$ /sqh-GFP \\
\hline
\end{tabular}

\section{Quantification of fixed imaging for border cell migration}

Quantification of the migration index of border cell migration was performed as described previously (Fox et al., 2020; Lamb et al., 2020). Briefly, measurements of S9 follicles were performed on 
confocal image stacks of follicles stained with anti-Hts and anti-Faslll or phalloidin. Measurements of migration distances were obtained from maximum projections of 2-4 confocal slices of deidentified 20 x confocal images using ImageJ software (Abramoff et al., 2004). Briefly, a line segment was drawn from the anterior end of the follicle to the front or posterior of the border cell cluster and the distance in microns measured, this was defined as the distance of border cell migration. Additionally, a line segment was drawn from the anterior end of the follicle to the anterior end of the main-body follicle cells and the distance measured, this was defined as the distance of the outer follicle cells. Lastly, the entire follicle length was measured along the anterior-posterior axis. The migration index was calculated in Excel (Microsoft, Redmond, WA) by dividing the border cell distance by the follicle cell distance. Cluster length was determined by measuring the distance from the front to the rear of the border cell cluster (detached cells were not included). Data was compiled, graphs generated, and statistical analysis performed using Prism (GraphPad Software).

\section{pMRLC quantifications}

Fluorescence intensity analyses were performed on maximum projections of 3 confocal slices of $40 x$ confocal images using ImageJ software. Concurrent Fascin or border cell staining (Hts and FasllI) was used to define the boundaries of the border cell cluster. For nurse cell intensity, three line segments per follicle were drawn across nurse cell-nurse cell membranes on maximum projections of 2-3 confocal slices of follicles stained for pMRLC and phalloidin. The fluorescent intensity peak for PMRLC was determined for each line and normalized to phalloidin intensity at the same point. These three values were then averaged for a single image. Averages were then normalized to the wild-type average for each experiment due to experimental variability (for example quantification see Figure 2-figure supplement 1). For border cell intensity, the border cell cluster was traced using the phalloidin stain and the mean fluorescence intensity for pMRLC was measured for this shape and this was then normalized to the mean fluorescence intensity of pMRLC of the same shape in the nurse cell cytoplasm (for example quantification see Figure 2-figure supplement 1). For the puncta number and length, puncta on the border cell cluster were manually counted and length measured from a maximum projection image using ImageJ software. Data was compiled, graphs generated, and statistical analysis performed using Prism (GraphPad Software).

\section{Live imaging}

Whole ovaries were dissected from flies fed wet yeast paste for 2-3 days and maintained at $25^{\circ} \mathrm{C}$ until the last $16-24 \mathrm{hr}$ when they were moved to $29^{\circ} \mathrm{C}$. Genotypes used for live imaging were sn28/ FM7; sqh-GFP and sn28/sn28; sqh-GFP. Ovaries were dissected in Stage 9 (S9) medium (Prasad and Montell, 2007): Schneider's medium (Life Technologies), 0.6 x penicillin/streptomycin (Life Technologies), $0.2 \mathrm{mg} / \mathrm{ml}$ insulin (Sigma-Aldrich, St. Louis, MO), and $15 \%$ fetal bovine serum (Atlanta Biologicals, Flowery Branch, GA). S9 follicles were hand dissected and embedded in $1.25 \%$ low-melt agarose (IBI Scientific, Peosta, IA) made with S9 media on a coverslip-bottom dish (MatTek, Ashland, MA). Just prior to live imaging, fresh S9 media was added to coverslip-bottom dish. Live imaging was performed with Zen software on a Zeiss 700 LSM mounted on an Axio Observer.Z1 using a Plan-Apochromat 20 x/0.8 working distance (WD) =0.55 M27 (Carl Zeiss Microscopy, Thornwood, NY) with a 2 x zoom. Images were acquired every 30 seconds for at least 1 hour for Sqh-GFP flies. Maximum projections (2-5 confocal slices), merge images, rotations, and cropping were performed using ImageJ software (Abramoff et al., 2004) To aid in visualization live imaging videos were brightened by $50 \%$ in Photoshop (Adobe, San Jose, CA).

\section{Quantification of live imaging}

Quantifications of live imaging videos were performed in ImageJ (Abramoff et al., 2004) using maximum projection of 2-5 confocal slices from time-lapse videos of border cell migration. For MRLC-GFP live imaging, puncta lifetime was defined by the amount of time elapsed from when a punctum first appeared to when it disappeared completely. Data were compiled, graphs generated, and statistical analysis performed using Prism (GraphPad Software). 
Atomic force microscopy (AFM) nanoindentation on Drosophila follicles

Whole ovaries were dissected from flies fed wet yeast paste for 2-3 days. Ovaries were dissected in S9 medium (Prasad and Montell, 2007), as described above. S9 follicles were hand isolated and mounted on poly-D-lysine coated $35 \mathrm{~mm}$ round glass coverslips. Force spectroscopy data were collected using a molecular force probe 3D (Asylum research) AFM in a liquid cell. AFM force spectroscopy was performed in a buffered solution within 1-2 hr after submersion. A new silicon nitride AFM probe (Bruker, DNP-10) was used for every experiment with a nominal spring constant of $0.12 \mathrm{~N} / \mathrm{m}$ and a half cone angle of 20 degrees. Actual spring constant was calibrated using the built-in thermal noise method prior to measurement collection in each experiment. S9 follicles were located using the top view video camera and AFM force versus indentation data were collected on the middle of the follicle. The force data were recorded with a $0.6-1.2 \mu \mathrm{m} / \mathrm{s}$ tip approach velocity and a maximum force ranging from 1 to $5 \mathrm{nN}$. For each genotype, two to three follicles were probed per experiment for three independent experiments; a total of six to nine follicles were probed per genotype. In each region, five to eight different positions with 2-10 $\mu \mathrm{m}$ separations were probed. For each position, 3-10 multiple repeated force curves were recorded. Two stiffness values of follicles were determined by fitting the approach data of two separate tip depth force-indentation curves to the rearranged form of the Hertzian elastic contact model (Heinrich, 1882). These two force-indentation ranges were selected to measure the stiffness of the basement membrane $(20-100 \mathrm{~nm})$ and underlying nurse cells (310-550 nm) and are similar to previous studies (Chlasta et al., 2017; Crest et al., 2017; Chen et al., 2019). Poisson's ratios of 0.5 and 0.25 were assumed for the follicles and AFM probe, respectively. The data analysis was carried out as in our previously reported work (Kruger et al., 2019; Bell et al., 2020; Kruger et al., 2020; McGowan et al., 2020).

\section{Pharmacological inhibition of Myosin in Drosophila follicles}

Flies were fed wet yeast paste for 2-3 days and maintained at room temperature. Ovaries of wild-

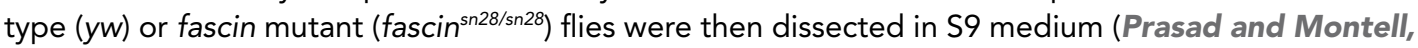
2007), as described above. Ovarioles were teased apart and then were incubated at room temperature for $2 \mathrm{hr}$ in either control media (S9 media + vehicle (DMSO)) or $200 \mu \mathrm{M}$ of Y-27632. After $2 \mathrm{hr}$, ovaries were rinsed three times with S9 media and then fixed and stained following the pMRLC staining protocol described above.

\section{Western blot}

Approximately 100 S9 follicles were dissected in room temperature Grace's insect media (Lonza, Walkersville, MD, USA or Thermo Fisher Scientific, Waltham, MA) and transferred to a $1.5 \mathrm{~mL}$ microcentrifuge tube containing $50 \mu \mathrm{L}$ of Grace's media. Grace's media was removed and replaced with $50 \mu \mathrm{L} 1 \times$ PBS, $50 \mu \mathrm{L} 2$ X SDS Sample Buffer was added and the tissue lysed by grinding with a plastic pestle. Ten $\mu \mathrm{L}$ of sample were loaded per lane on either $8 \%$ or $10 \%$ SDS-PAGE gels. Western blots were performed using standard methods. The membranes were cut prior to incubation with primary antibodies to allow for two proteins to be simultaneously assessed. The following primary antibodies were used: rat $\alpha$-Vasa Spradling, A.C.; obtained from the Developmental Studies Hybridoma Bank (DSHB), 1:100 and rabbit $\alpha$-Zipper (Karess, R.; Institut Jacques Monod, Paris, France; Wheatley et al., 1995), 1:10,000. For the Vasa primary antibody incubations, the antibody was diluted in $5 \%$ non-fat milk in $1 \times$ Tris-buffered saline and $0.1 \%$ Tween-20. For the Zipper primary antibody incubations, the antibody was diluted in $5 \%$ Bovine Serum Albumin in $1 \times$ Tris-buffered saline and $0.1 \%$ Tween-20. The following secondary antibodies were used: Peroxidase-AffiniPure Goat Anti-Rat IgG $(H+L), 1: 5000$ and Peroxidase-AffiniPure Goat Anti-Rabbit IgG $(H+L), 1: 10,000$ (Jackson ImmunoResearch Laboratories, West Grove, PA, USA). Blots were developed with SuperSignal West Pico or Femto Chemiluminescent Substrate (Thermo Scientific, Waltham, MA, USA) and imaged using the Amersham Imager 600 (GE Healthcare Life Sciences, Chicago, IL). Bands were quantified using densitometry analysis in ImageJ (Abramoff et al., 2004). Zipper levels were assessed using four independent, biological samples per genotype, and statistical significance was determined using a two-sample t-test with unequal variance in Excel (Microsoft, Redmond, WA, USA). 


\section{Acknowledgements}

We thank the Westside Fly Group and Dunnwald lab for helpful discussions, and the Tootle lab for helpful discussions and careful review of the manuscript. Stocks obtained from the Bloomington Drosophila Stock Center (NIH P40OD018537) were used in this study. Information Technology Services - Research Services provided data storage support. This project is supported by National Institutes of Health R01GM116885. MCL was partially supported by the University of lowa Summer Graduate Fellowship.

\section{Additional information}

Funding

\begin{tabular}{lll} 
Funder & Grant reference number & Author \\
\hline National Institute of & R01GM116885 & Maureen C Lamb \\
General Medical Sciences & & Samuel Q Mellentine \\
& & Tina L Tootle \\
\hline
\end{tabular}

The funders had no role in study design, data collection and interpretation, or the decision to submit the work for publication.

Author contributions

Maureen C Lamb, Conceptualization, Formal analysis, Investigation, Methodology, Visualization, Writing - original draft; Chathuri P Kaluarachchi, Formal analysis, Investigation, Writing - review and editing; Thiranjeewa I Lansakara, Formal analysis, Investigation, Methodology; Samuel Q Mellentine, Formal analysis, Investigation; Yiling Lan, Formal analysis; Alexei V Tivanski, Supervision, Writing - review and editing; Tina L Tootle, Conceptualization, Funding acquisition, Supervision, Writing review and editing

\section{Author ORCIDs}

Maureen C Lamb (iD http://orcid.org/0000-0002-4522-1910

Chathuri P Kaluarachchi (iD http://orcid.org/0000-0003-2538-3952

Tina L Tootle (iD http://orcid.org/0000-0002-1515-9538

Decision letter and Author response

Decision letter https://doi.org/10.7554/eLife.69836.sa1

Author response https://doi.org/10.7554/eLife.69836.sa2

\section{Additional files}

Supplementary files

- Transparent reporting form

Data availability

All data generated or analysed during this study are included in the manuscript as Figure-specific source data files.

\section{References}

Abramoff MD, Magalhaes P, Ram S. 2004. Image processing with ImageJ. Biophotonics Int 11: 36-42.

Adams JC, Clelland JD, Collett GD, Matsumura F, Yamashiro S, Zhang L. 1999. Cell-matrix adhesions differentially regulate fascin phosphorylation. Molecular Biology of the Cell 10: 4177-4190. DOI: https://doi. org/10.1091/mbc.10.12.4177, PMID: 10588651

Aguilar-Cuenca R, Juanes-García A, Vicente-Manzanares M. 2014. Myosin II in mechanotransduction: master and commander of cell migration, morphogenesis, and cancer. Cellular and Molecular Life Sciences 71: 479-492. DOI: https://doi.org/10.1007/s00018-013-1439-5, PMID: 23934154

Alburquerque-González B, Bernabé-García M, Montoro-García S, Bernabé-García Á, Rodrigues PC, Ruiz Sanz J, López-Calderón FF, Luque I, Nicolas FJ, Cayuela ML, Salo T, Pérez-Sánchez H, Conesa-Zamora P. 2020. New 
role of the antidepressant imipramine as a Fascin1 inhibitor in colorectal cancer cells. Experimental \& Molecular Medicine 52: 281-292. DOI: https://doi.org/10.1038/s12276-020-0389-x, PMID: 32080340

Aranjuez G, Burtscher A, Sawant K, Majumder P, McDonald JA. 2016. Dynamic myosin activation promotes collective morphology and migration by locally balancing oppositional forces from surrounding tissue.

Molecular Biology of the Cell 27: 1898-1910. DOI: https://doi.org/10.1091/mbc.e15-10-0744, PMID: 27122602

Barriga EH, Franze K, Charras G, Mayor R. 2018. Tissue stiffening coordinates morphogenesis by triggering collective cell migration in vivo. Nature 554: 523-527. DOI: https://doi.org/10.1038/nature25742, PMID: 29443958

Bell KJ, Lansakara TI, Crawford R, Monroe TB, Tivanski AV, Salem AK, Stevens LL. 2020. Mechanical cues protect against silica nanoparticle exposure in SH-SY5Y neuroblastoma. Toxicology in Vitro: An International Journal Published in Association with BIBRA 7: 105031. DOI: https://doi.org/10.1016/j.tiv.2020.105031

Bianco A, Poukkula M, Cliffe A, Mathieu J, Luque CM, Fulga TA, Rørth P. 2007. Two distinct modes of guidance signalling during collective migration of border cells. Nature 448: 362-365. DOI: https://doi.org/10.1038/ nature05965, PMID: 17637670

Butcher DT, Alliston T, Weaver VM. 2009. A tense situation: forcing tumour progression. Nature Reviews. Cancer 9: 108-122. DOI: https://doi.org/10.1038/nrc2544, PMID: 19165226

Cai D, Chen SC, Prasad M, He L, Wang X, Choesmel-Cadamuro V, Sawyer JK, Danuser G, Montell DJ. 2014. Mechanical feedback through E-cadherin promotes direction sensing during collective cell migration. Cell 157: 1146-1159. DOI: https://doi.org/10.1016/j.cell.2014.03.045, PMID: 24855950

Cant K, Knowles BA, Mooseker MS, Cooley L. 1994. Drosophila singed, a fascin homolog, is required for actin bundle formation during oogenesis and bristle extension. The Journal of Cell Biology 125: 369-380. DOI: https://doi.org/10.1083/jcb.125.2.369, PMID: 8163553

Chandler C, Liu T, Buckanovich R, Coffman LG. 2019. The double edge sword of fibrosis in cancer. Translational Research 209: 55-67. DOI: https://doi.org/10.1016/j.trsl.2019.02.006, PMID: 30871956

Chang SS, Rape AD, Wong SA, Guo WH, Wang YL. 2019. Migration regulates cellular mechanical states. Molecular Biology of the Cell 30: 3104-3111. DOI: https://doi.org/10.1091/mbc.E19-02-0099, PMID: 31693433

Chen DY, Crest J, Streichan SJ, Bilder D. 2019. Extracellular matrix stiffness cues junctional remodeling for 3D tissue elongation. Nature Communications 10: 3339. DOI: https://doi.org/10.1038/s41467-019-10874-x, PMID: 31350387

Chlasta J, Milani P, Runel G, Duteyrat J-L, Arias L, Lamiré L-A, Boudaoud A, Grammont M. 2017. Variations in basement membrane mechanics are linked to epithelial morphogenesis. Development 144: 4350-4362. DOI: https://doi.org/10.1242/dev.152652, PMID: 29038305

Cox TR, Erler JT. 2014. Molecular pathways: connecting fibrosis and solid tumor metastasis. Clinical Cancer Research 20: 3637-3643. DOI: https://doi.org/10.1158/1078-0432.CCR-13-1059, PMID: 25028505

Crest J, Diz-Muñoz A, Chen D-Y, Fletcher DA, Bilder D. 2017. Organ sculpting by patterned extracellular matrix stiffness. eLife 6: e24958. DOI: https://doi.org/10.7554/eLife.24958, PMID: 28653906

Dai W, Guo X, Cao Y, Mondo JA, Campanale JP, Montell BJ, Burrous H, Streichan S, Gov N, Rappel WJ, Montell DJ. 2020. Tissue topography steers migrating Drosophila border cells. Science 370: 987-990. DOI: https://doi.org/10.1126/science.aaz4741, PMID: 33214282

De Pascalis C, Etienne-Manneville S. 2017. Single and collective cell migration: the mechanics of adhesions. Molecular Biology of the Cell 28: 1833-1846. DOI: https://doi.org/10.1091/mbc.e17-03-0134, PMID: 28684609

Di Martino J, Henriet E, Ezzoukhry Z, Goetz JG, Moreau V, Saltel F. 2016. The microenvironment controls invadosome plasticity. Journal of Cell Science 129: 1759-1768. DOI: https://doi.org/10.1242/jcs.182329, PMID: 27029343

Dinkins MB, Fratto VM, Lemosy EK. 2008. tegrin alpha chains exhibit distinct temporal and spatial localization patterns in epithelial cells of the Drosophila ovary. Developmental Dynamics 237: 3927-3939. DOI: https://doi. org/10.1002/dvdy.21802, PMID: 19035354

Doyle AD, Sykora DJ, Pacheco GG, Kutys ML, Yamada KM. 2021. 3D mesenchymal cell migration is driven by anterior cellular contraction that generates an extracellular matrix prestrain. Developmental Cell 56: 826-841.. DOI: https://doi.org/10.1016/j.devcel.2021.02.017, PMID: 33705692

Eble JA, Niland S. 2019. The extracellular matrix in tumor progression and metastasis. Clinical \& Experimental Metastasis 36: 171-198. DOI: https://doi.org/10.1007/s10585-019-09966-1, PMID: 30972526

Edwards KA, Kiehart DP. 1996. Drosophila nonmuscle myosin II has multiple essential roles in imaginal disc and egg chamber morphogenesis. Development 122: 1499-1511. DOI: https://doi.org/10.1242/dev.122.5.1499, PMID: 8625837

Elkhatib N, Neu MB, Zensen C, Schmoller KM, Louvard D, Bausch AR, Betz T, Vignjevic DM. 2014. Fascin plays a role in stress fiber organization and focal adhesion disassembly. Current Biology 24: 1492-1499. DOI: https:// doi.org/10.1016/j.cub.2014.05.023, PMID: 24930964

Emon B, Bauer J, Jain Y, Jung B, Saif T. 2018. Biophysics of Tumor Microenvironment and Cancer Metastasis - A Mini Review. Computational and Structural Biotechnology Journal 16: 279-287. DOI: https://doi.org/10.1016/j. csbj.2018.07.003, PMID: 30128085

Fox EF, Lamb MC, Mellentine SQ, Tootle TL. 2020. Prostaglandins regulate invasive, collective border cell migration. Molecular Biology of the Cell 31: 1584-1594. DOl: https://doi.org/10.1091/mbc.E19-10-0578, PMID: 32432969

Friedl P, Gilmour D. 2009. Collective cell migration in morphogenesis, regeneration and cancer. Nature Reviews. Molecular Cell Biology 10: 445-457. DOI: https://doi.org/10.1038/nrm2720, PMID: 19546857 
Fulga TA, Rørth P. 2002. vasive cell migration is initiated by guided growth of long cellular extensions. Nature Cell Biology 4: 715-719. DOI: https://doi.org/10.1038/ncb848, PMID: 12198500

Gasparski AN, Ozarkar S, Beningo KA. 2017. Transient mechanical strain promotes the maturation of invadopodia and enhances cancer cell invasion in vitro. Journal of Cell Science 130: 1965-1978. DOI: https:// doi.org/10.1242/jcs.199760, PMID: 28446539

Groen CM, Jayo A, Parsons M, Tootle TL. 2015. Prostaglandins regulate nuclear localization of Fascin and its function in nucleolar architecture. Molecular Biology of the Cell 26: 1901-1917. DOI: https://doi.org/10.1091/ mbc.E14-09-1384, PMID: 25808493

Grothey A, Hashizume R, Ji H, Tubb BE, Patrick CW, Yu D, Mooney EE, McCrea PD. 2000. C-erbB-2/ HER-2 upregulates fascin, an actin-bundling protein associated with cell motility, in human breast cancer cell lines. Oncogene 19: 4864-4875. DOI: https://doi.org/10.1038/sj.onc.1203838, PMID: 11039904

Hall MS, Alisafaei F, Ban E, Feng X, Hui CY, Shenoy VB, Wu M. 2016. Fibrous nonlinear elasticity enables positive mechanical feedback between cells and ECMs. PNAS 113: 14043-14048. DOI: https://doi.org/10.1073/pnas. 1613058113, PMID: 27872289

Hashimoto Y, Parsons M, Adams JC. 2007. Dual actin-bundling and protein kinase C-binding activities of fascin regulate carcinoma cell migration downstream of Rac and contribute to metastasis. Molecular Biology of the Cell 18: 4591-4602. DOI: https://doi.org/10.1091/mbc.e07-02-0157, PMID: 17855511

Hashimoto Y, Kim DJ, Adams JC. 2011. The roles of fascins in health and disease. The Journal of Pathology 224: 289-300. DOI: https://doi.org/10.1002/path.2894, PMID: 21618240

He L, Wang X, Tang HL, Montell DJ. 2010. Tissue elongation requires oscillating contractions of a basal actomyosin network. Nature Cell Biology 12: 1133-1142. DOI: https://doi.org/10.1038/ncb2124, PMID: 21102441

Heinrich H. 1882. Ueber die Berührung fester elastischer Körper. Journal Für Die Reine Und Angewandte Mathematik 1882: 156-171.

Jayo A, Parsons M. 2010. Fascin: a key regulator of cytoskeletal dynamics. The International Journal of Biochemistry \& Cell Biology 42: 1614-1617. DOI: https://doi.org/10.1016/j.biocel.2010.06.019, PMID: 20601080

Jayo A, Malboubi M, Antoku S, Chang W, Ortiz-Zapater E, Groen C, Pfisterer K, Tootle T, Charras G, Gundersen GG, Parsons M. 2016. Fascin Regulates Nuclear Movement and Deformation in Migrating Cells. Developmental Cell 38: 371-383. DOI: https://doi.org/10.1016/j. devcel.2016.07.021, PMID: 27554857

Kreplak L. 2016. troduction to Atomic Force Microscopy (AFM) in Biology. Current Protocols in Protein Science 85: 17. DOI: https://doi.org/10.1002/cpps.14

Kruger TM, Bell KJ, Lansakara TI, Tivanski AV, Doorn JA, Stevens LL. 2019. Reduced Extracellular Matrix Stiffness Prompts SH-SY5Y Cell Softening and Actin Turnover To Selectively Increase A $\beta(1-42)$ Endocytosis. ACS Chemical Neuroscience 10: 1284-1293. DOI: https://doi.org/10.1021/acschemneuro.8b00366, PMID: 30499651

Kruger TM, Bell KJ, Lansakara TI, Tivanski AV, Doorn JA, Stevens LL. 2020. A Soft Mechanical Phenotype of SH-SY5Y Neuroblastoma and Primary Human Neurons Is Resilient to Oligomeric Aß(1-42) Injury. ACS Chemical Neuroscience 11: 840-850. DOI: https://doi.org/10.1021/acschemneuro.9b00401, PMID: 32058688

Lamb MC, Anliker KK, Tootle TL. 2020. Fascin regulates protrusions and delamination to mediate invasive, collective cell migration in vivo. Developmental Dynamics 249: 961-982. DOI: https://doi.org/10.1002/dvdy. 186, PMID: 32352613

Lamb MC, Tootle TL. 2020. Fascin in Cell Migration: More Than an Actin Bundling Protein. Biology 9: E403. DOI: https://doi.org/10.3390/biology9110403, PMID: 33212856

Li Ang, Dawson JC, Forero-Vargas M, Spence HJ, Yu X, König I, Anderson K, Machesky LM. 2010. The actinbundling protein fascin stabilizes actin in invadopodia and potentiates protrusive invasion. Current Biology 20: 339-345. DOI: https://doi.org/10.1016/j.cub.2009.12.035, PMID: 20137952

Li A, Morton JP, Ma Y, Karim SA, Zhou Y, Faller WJ, Woodham EF, Morris HT, Stevenson RP, Juin A, Jamieson NB, MacKay CJ, Carter CR, Leung HY, Yamashiro S, Blyth K, Sansom OJ, Machesky LM. 2014. Fascin is regulated by slug, promotes progression of pancreatic cancer in mice, and is associated with patient outcomes. Gastroenterology 146: 1386-1396.. DOI: https://doi.org/10.1053/j.gastro.2014.01.046

Llense F, Martín-Blanco E. 2008. JNK signaling controls border cell cluster integrity and collective cell migration. Current Biology 18: 538-544. DOI: https://doi.org/10.1016/j.cub.2008.03.029, PMID: 18394890

Lo CM, Wang HB, Dembo M, Wang YL. 2000. Cell movement is guided by the rigidity of the substrate. Biophysical Journal 79: 144-152. DOI: https://doi.org/10.1016/S0006-3495(00)76279-5, PMID: 10866943

Ma Y, Machesky LM. 2015. Fascin1 in carcinomas: Its regulation and prognostic value. Ternational Journal of Cancer 137: 2534-2544. DOI: https://doi.org/10.1002/ijc.29260, PMID: 25302416

Majumder P, Aranjuez G, Amick J, McDonald JA. 2012. Par-1 controls myosin-Il activity through myosin phosphatase to regulate border cell migration. Current Biology 22: 363-372. DOI: https://doi.org/10.1016/j. cub.2012.01.037, PMID: 22326025

Martinez JS, Schlenoff JB, Keller TCS. 2016. Collective epithelial cell sheet adhesion and migration on polyelectrolyte multilayers with uniform and gradients of compliance. Experimental Cell Research 346: 17-29. DOI: https://doi.org/10.1016/j.yexcr.2016.06.002, PMID: 27292313

McGowan SE, Lansakara TI, McCoy DM, Zhu L, Tivanski AV. 2020. Platelet-derived Growth Factor- $\alpha$ and Neuropilin-1 Mediate Lung Fibroblast Response to Rigid Collagen Fibers. American Journal of Respiratory Cell and Molecular Biology 62: 454-465. DOI: https://doi.org/10.1165/rcmb.2019-0173OC, PMID: 31913651 
Medioni C, Noselli S. 2005. Dynamics of the basement membrane in invasive epithelial clusters in Drosophila. Development 132: 3069-3077. DOI: https://doi.org/10.1242/dev.01886, PMID: 15944190

Mierke CT. 2020. Mechanical Cues Affect Migration and Invasion of Cells From Three Different Directions. Frontiers in Cell and Developmental Biology 8: 583226. DOI: https://doi.org/10.3389/fcell.2020.583226, PMID: 33043017

Minn AJ, Gupta GP, Siegel PM, Bos PD, Shu W, Giri DD, Viale A, Olshen AB, Gerald WL, Massagué J. 2005. Genes that mediate breast cancer metastasis to lung. Nature 436: 518-524. DOI: https://doi.org/10.1038/ nature03799, PMID: 16049480

Mishra AK, Mondo JA, Campanale JP, Montell DJ. 2019. Coordination of protrusion dynamics within and between collectively migrating border cells by myosin II. Molecular Biology of the Cell 30: 2490-2502. DOI: https://doi.org/10.1091/mbc.E19-02-0124, PMID: 31390285

Mohan K, Luo T, Robinson DN, Iglesias PA. 2015. Cell shape regulation through mechanosensory feedback control. Journal of the Royal Society, Interface 12: 20150512. DOI: https://doi.org/10.1098/rsif.2015.0512, PMID: 26224568

Montell DJ. 2003. Border-cell migration: the race is on. Nature Reviews. Molecular Cell Biology 4: 13-24. DOI: https://doi.org/10.1038/nrm1006, PMID: 12511865

Montell DJ, Yoon WH, Starz-Gaiano M. 2012. Group choreography: mechanisms orchestrating the collective movement of border cells. Nature Reviews. Molecular Cell Biology 13: 631-645. DOI: https://doi.org/10.1038/ nrm3433, PMID: 23000794

Nieto MA, Cano A. 2012. The epithelial-mesenchymal transition under control: global programs to regulate epithelial plasticity. Seminars in Cancer Biology 22: 361-368. DOI: https://doi.org/10.1016/j.semcancer.2012. 05.003, PMID: 22613485

Niewiadomska P, Godt D, Tepass U. 1999. DE-Cadherin is required for intercellular motility during Drosophila oogenesis. The Journal of Cell Biology 144: 533-547. DOI: https://doi.org/10.1083/jcb.144.3.533, PMID: 9971747

Oakes PW. 2018. Balancing forces in migration. Current Opinion in Cell Biology 54: 43-49. DOI: https://doi.org/ 10.1016/j.ceb.2018.04.006, PMID: 29723736

Ono S, Yamakita Y, Yamashiro S, Matsudaira PT, Gnarra JR, Obinata T, Matsumura F. 1997. Identification of an actin binding region and a protein kinase $\mathrm{C}$ phosphorylation site on human fascin. The Journal of Biological Chemistry 272: 2527-2533. DOI: https://doi.org/10.1074/jbc.272.4.2527, PMID: 8999969

Parekh A, Weaver AM. 2016. Regulation of invadopodia by mechanical signaling. Experimental Cell Research 343: 89-95. DOI: https://doi.org/10.1016/j.yexcr.2015.10.038, PMID: 26546985

Patel NH, Snow PM, Goodman CS. 1987. Characterization and cloning of fasciclin III: a glycoprotein expressed on a subset of neurons and axon pathways in Drosophila. Cell 48: 975-988. DOI: https://doi.org/10.1016/ 0092-8674(87)90706-9, PMID: 3548998

Piersma B, Hayward MK, Weaver VM. 2020. Fibrosis and cancer: A strained relationship. Biochimica et Biophysica Acta. Reviews on Cancer 1873: 188356. DOI: https://doi.org/10.1016/j.bbcan.2020.188356, PMID: 32147542

Platt JL, Michael AF. 1983. Retardation of fading and enhancement of intensity of immunofluorescence by p-phenylenediamine. The Journal of Histochemistry and Cytochemistry 31: 840-842. DOI: https://doi.org/10. 1177/31.6.6341464, PMID: 6341464

Prasad M, Montell DJ. 2007. Cellular and molecular mechanisms of border cell migration analyzed using time-lapse live-cell imaging. Developmental Cell 12: 997-1005. DOl: https://doi.org/10.1016/j.devcel.2007.03. 021, PMID: 17543870

Ren Y, Zhang Y, Liu J, Liu P, Yang J, Guo D, Tang A, Tao J. 2021. Matrix hardness regulates the cancer cell malignant progression through cytoskeletal network. Biochemical and Biophysical Research Communications 541: 95-101. DOI: https://doi.org/10.1016/j.bbrc.2021.01.014, PMID: 33493685

Schindelin J, Arganda-Carreras I, Frise E, Kaynig V, Longair M, Pietzsch T, Preibisch S, Rueden C, Saalfeld S, Schmid B, Tinevez JY, White DJ, Hartenstein V, Eliceiri K, Tomancak P, Cardona A. 2012. Fiji: an open-source platform for biological-image analysis. Nature Methods 9: 676-682. DOI: https://doi.org/10.1038/nmeth.2019, PMID: 22743772

Shellard A, Mayor R. 2021. Durotaxis: The Hard Path from In Vitro to In Vivo. Developmental Cell 56: 227-239. DOI: https://doi.org/10.1016/j.devcel.2020.11.019, PMID: 33290722

Spradling A. 1993. Developmental Genetics of Oogenesis, The Development of Drosophila Melanogastor. Cold Spring Harbor Laboratory Press.

Stuelten CH, Parent CA, Montell DJ. 2018. Cell motility in cancer invasion and metastasis: insights from simple model organisms. Nature Reviews. Cancer 18: 296-312. DOI: https://doi.org/10.1038/nrc.2018.15, PMID: 29546880

Sunyer R, Conte V, Escribano J, Elosegui-Artola A, Labernadie A, Valon L, Navajas D, García-Aznar JM, Muñoz JJ, Roca-Cusachs $P$, Trepat X. 2016. Collective cell durotaxis emerges from long-range intercellular force transmission. Science 353: 1157-1161. DOI: https://doi.org/10.1126/science.aaf7119, PMID: 27609894

Sunyer R, Trepat X. 2020. Durotaxis. Current Biology 30: R383-R387. DOI: https://doi.org/10.1016/j.cub.2020. 03.051, PMID: 32369745

Telley IA, Gáspár I, Ephrussi A, Surrey T. 2012. Aster migration determines the length scale of nuclear separation in the Drosophila syncytial embryo. The Journal of Cell Biology 197: 887-895. DOI: https://doi.org/10.1083/ jcb.201204019, PMID: 22711698 
Tse JM, Cheng G, Tyrrell JA, Wilcox-Adelman SA, Boucher Y, Jain RK, Munn LL. 2012. Mechanical compression drives cancer cells toward invasive phenotype. PNAS 109: 911-916. DOI: https://doi.org/10.1073/pnas. 1118910109, PMID: 22203958

van Helvert S, Friedl P. 2016. Strain Stiffening of Fibrillar Collagen during Individual and Collective Cell Migration Identified by AFM Nanoindentation. ACS Applied Materials \& Interfaces 8: 21946-21955. DOI: https://doi.org/10.1021/acsami.6b01755, PMID: 27128771

van Helvert S, Storm C, Friedl P. 2018. Mechanoreciprocity in cell migration. Nature Cell Biology 20: 8-20. DOI: https://doi.org/10.1038/s41556-017-0012-0, PMID: 29269951

Vicente-Manzanares M, Ma X, Adelstein RS, Horwitz AR. 2009. Non-muscle myosin II takes centre stage in cell adhesion and migration. Nature Reviews. Molecular Cell Biology 10: 778-790. DOI: https://doi.org/10.1038/ nrm2786, PMID: 19851336

Villari G, Jayo A, Zanet J, Fitch B, Serrels B, Frame M, Stramer BM, Goult BT, Parsons M. 2015. A direct interaction between fascin and microtubules contributes to adhesion dynamics and cell migration. Journal of Cell Science 128: 4601-4614. DOI: https://doi.org/10.1242/jcs.175760, PMID: 26542021

Wheatley S, Kulkarni S, Karess R. 1995. Drosophila nonmuscle myosin II is required for rapid cytoplasmic transport during oogenesis and for axial nuclear migration in early embryos. Development 121: 1937-1946 PMID: 7601006.,

Wolf K, Wu YI, Liu Y, Geiger J, Tam E, Overall C, Stack MS, Friedl P. 2007. Multi-step pericellular proteolysis controls the transition from individual to collective cancer cell invasion. Nature Cell Biology 9: 893-904. DOI: https://doi.org/10.1038/ncb1616, PMID: 17618273

Yamakita Y, Ono S, Matsumura F, Yamashiro S. 1996. Phosphorylation of human fascin inhibits its actin binding and bundling activities. The Journal of Biological Chemistry 271: 12632-12638. DOI: https://doi.org/10.1074/ jbc.271.21.12632, PMID: 8647875

Zaccai M, Lipshitz HD. 1996. Differential distributions of two adducin-like protein isoforms in the Drosophila ovary and early embryo. Zygote 4: 159-166. DOI: https://doi.org/10.1017/s096719940000304x, PMID: 8913030

Zanet J, Stramer B, Millard T, Martin P, Payre F, Plaza S. 2009. Fascin is required for blood cell migration during Drosophila embryogenesis. Development 136: 2557-2565. DOI: https://doi.org/10.1242/dev.036517, PMID: 19592575

Zanet J, Jayo A, Plaza S, Millard T, Parsons M, Stramer B. 2012. Fascin promotes filopodia formation independent of its role in actin bundling. The Journal of Cell Biology 197: 477-486. DOI: https://doi.org/10. 1083/jcb.201110135, PMID: 22564415 